\title{
Visualization of Dopamine Transporter Trafficking in Live Neurons by Use of Fluorescent Cocaine Analogs
}

\author{
Jacob Eriksen, ${ }^{1 \star}$ Søren G. F. Rasmussen, ${ }^{1 *}$ Trine Nygaard Rasmussen, ${ }^{1}$ Christian Bjerggaard Vaegter, ${ }^{1}$ Joo Hwan Cha, ${ }^{2}$ \\ Mu-Fa Zou, ${ }^{2}$ Amy Hauck Newman, ${ }^{2}$ and Ulrik Gether ${ }^{1}$ \\ ${ }^{1}$ Molecular Neuropharmacology Group and Center for Pharmacogenomics, Department of Neuroscience and Pharmacology, The Panum Institute, \\ University of Copenhagen, DK-2200 Copenhagen N, Denmark, and ${ }^{2}$ Medicinal Chemistry Section, National Institute on Drug Abuse-Intramural Research \\ Program, National Institutes of Health, Baltimore, Maryland 21224
}

The dopamine transporter (DAT) mediates reuptake of dopamine from the synaptic cleft and is a target for widely abused psychostimulants such as cocaine and amphetamine. Nonetheless, little is known about the cellular distribution and trafficking of natively expressed DAT. Here we use novel fluorescently tagged cocaine analogs to visualize DAT and DAT trafficking in cultured live midbrain dopaminergic neurons. The fluorescent tags were extended from the tropane $\mathrm{N}$-position of $2 \beta$-carbomethoxy-3 $\beta$ - $(3,4$-dichlorophenyl)tropane using an ethylamino-linker. The rhodamine-, OR Green-, or Cy3-labeled ligands had high binding affinity for DAT and enabled specific labeling of DAT in live neurons and visualization by confocal imaging. In the dopaminergic neurons, DAT was uniformly distributed in the plasma membrane of the soma, the neuronal extensions, and varicosities along these extensions. FRAP (fluorescence recovery after photobleaching) experiments demonstrated bidirectional movement of DAT in the extensions and indicated that DAT is highly mobile both in the extensions and in the varicosities (immobile fraction less than $\sim 30 \%$ ). DAT was constitutively internalized into vesicular structures likely representing intracellular transporter pools. The internalization was blocked by lentiviral-mediated expression of dominant-negative dynamin and internalized DAT displayed partial colocalization with the early endosomal marker EGFP-Rab5 and with the transferrin receptor. DAT internalization and function was not affected by activation of protein kinase C (PKC) with phorbol12-myristate-13-acetate (PMA) or by inhibition with staurosporine or GF109203X. These data are in contrast to findings for DAT in transfected heterologous cells and challenge the paradigm that trafficking and cellular distribution of endogenous DAT is subject to regulation by PKC.

\section{Introduction}

The dopamine transporter (DAT) mediates reuptake of dopamine from the synaptic cleft and in this way terminates dopaminergic signaling (Chen et al., 2004; Gether et al., 2006; Torres and Amara, 2007). Alteration in dopamine signaling and DAT function is coupled to neurological and psychiatric diseases including schizophrenia, bipolar disorder, ADHD (attention-deficit hyperactivity disorder), Tourette's syndrome, and Parkinson's disease (Gainetdinov and Caron, 2003; Torres et al., 2003; Gether et al., 2006). DAT is also the principle target for widely abused psychostimulants, such as cocaine and amphetamine (Chen et al., 2004; Gether et al., 2006; Torres and Amara, 2007). The transporter

Received Sept. 2, 2008; revised April 6, 2009; accepted April 15, 2009.

This work was supported in part by National Institutes of Health (NIH) Grant P01 DA 12408 (U.G.), the Lundbeck Foundation (U.G.), the Danish Medical Research Councils (U.G.), "Fabrikant Vilhelm Pedersen og Hustrus Mindelegat" (U.G.), and National Institute on Drug Abuse Intramural Research Program (NIDA-IRP), NIH (A.H.N.). We thank Dr. Erika Adkins for critical advice on the FRAP measurements and Dr. Alexandra Newton for providing the CDNA encoding CKAR. We thank Donna Czerny and Nabeela Khadim for excellent technical assistance. The MALDI-TOF spectra were obtained by Dr. Amina Woods, NIDA-IRP.

*J.E. and S.G.F.R. contributed equally to this work.

Correspondence should be addressed to Dr. Ulrik Gether, Molecular Neuropharmacology Group and Center for Pharmacogenomics, Department of Neuroscience and Pharmacology, The Panum Institute, University of Copenhagen, DK-2200 Copenhagen N, Denmark. E-mail: gether@sund.ku.dk.

D0I:10.1523/JNEUROSCI.4177-08.2009

Copyright $\odot 2009$ Society for Neuroscience $\quad$ 0270-6474/09/296794-15\$15.00/0 belongs to the family of neurotransmitter:sodium symporters (NSS) [also called the SLC6 (solute carrier 6) family or $\mathrm{Na}^{+} / \mathrm{Cl}^{-}$ coupled transporters] that in addition includes the transporters for norepinephrine, serotonin, glycine, and GABA. NSS proteins use the transmembrane $\mathrm{Na}^{+}$gradient as a driving force for transport of substrate and are characterized by additional cotransport of $\mathrm{Cl}^{-}$(Chen et al., 2004; Gether et al., 2006; Torres and Amara, 2007; Zomot et al., 2007).

It is assumed that DAT is subject to specific cellular regulation ensuring proper availability and activity of the transporter in the neuron. The most widely described regulatory mechanism involves redistribution of the transporter to an intracellular compartment in response to protein kinase C (PKC) activation (Daniels and Amara, 1999; Melikian and Buckley, 1999; Blakely and Bauman, 2000; Granas et al., 2003; Miranda et al., 2007). DAT trafficking might also be regulated by other protein kinases such as mitogen-activated protein kinase (MAPK) and Akt (Morón et al., 2003; Garcia et al., 2005) as well as being affected by substrates and inhibitors. Both dopamine and amphetamine have been shown to cause transporter internalization (Saunders et al., 2000; Chi and Reith, 2003), whereas cocaine was shown to acutely enhance DAT surface availability although the effect was relatively modest (Daws et al., 2002). A constitutive internalization signal in the DAT C terminus has recently been identified (Holton et al., 2005; Sorkina et al., 2005); however, it is not 


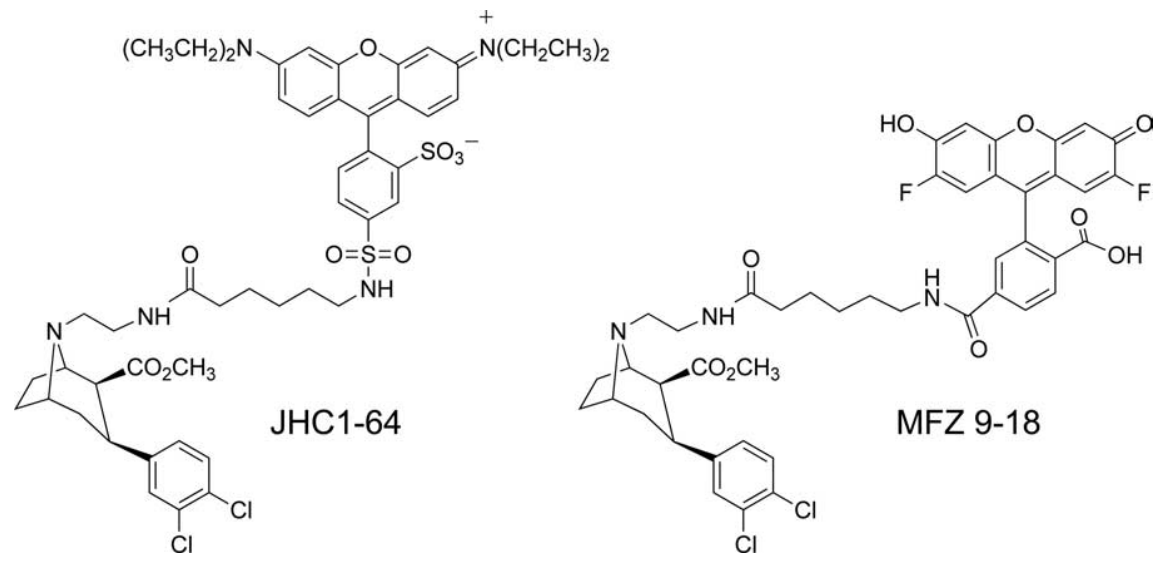

Figure 1. Structure of fluorescently labeled cocaine analogs. Left, The rhodamine conjugate JHC 1-64. Right, The Oregon Green conjugate MFZ 9-18. JHC 1-64 was synthesized as described previously (Cha et al., 2005). MFZ 9-18 was synthesized as described in Materials and Methods. For both compounds, the fluorescent tag was extended from the N-position of $2 \beta$ carbomethoxy-3 $\beta$-(3,4-dichlorophenyl)tropane using an ethylamino-linker.

known whether this signal operates in the natively expressed transporter.

The vast majority of studies performed on DAT trafficking have been performed in non-neuronal and transfected heterologous expression systems and not on endogenously expressed transporter. One major problem is the relatively low number of dopaminergic and thereby DAT expressing neurons in the brain. As a consequence, it is generally difficult to obtain neuronal cultures containing a high fraction of dopaminergic neurons (di Porzio et al., 1987; Silva et al., 1988; Rayport et al., 1992; Ingram et al., 2002) making qualitative and quantitative studies of DAT regulation difficult. It has also appeared notoriously difficult to develop an efficient antibody against an extracellular epitope of the DAT and, thus, labeling of endogenous DAT in living cells has not been possible. To develop tools that might permit visualization of DAT in living cells, we recently synthesized a series of rhodamine-coupled fluorescent cocaine analogs (Cha et al., 2005). Here we use one of these ligands together with two new fluorescent cocaine analogs to visualize endogenously expressed DAT and its trafficking in primary cultures of rat midbrain dopaminergic neurons.

\section{Materials and Methods}

Synthesis of fluorescent ligands. JHC 1-64 was synthesized as previously described (Cha et al., 2005). MFZ 9-17 was synthesized by adding diisopropylethylamine $(6.0 \mathrm{mg}, 47.0 \mu \mathrm{mol})$ to a solution of $(-)-\mathrm{N}-(2-$ aminoethyl)- $2 \beta$-carbomethoxy-3 $\beta$-(3.4-dichlorophenyl)-tropane (Cha et al., 2005) $(6 \mathrm{mg}, 16.85 \mu \mathrm{mol})$ and Cy3 $N$-hydroxysuccinimide ester $(10 \mathrm{mg}$, $13.05 \mu \mathrm{mol})$ in DMF $(2 \mathrm{ml})$ and the mixture was stirred overnight at $40-$ $45^{\circ} \mathrm{C}$. The solvent was then removed under reduced pressure and the resulting residue was purified directly by preparative thin-layer chromatography, eluting with $\mathrm{CHCl}_{3}-\mathrm{MeOH}-28 \% \mathrm{NH}_{4} \mathrm{OH}$ (70:30:1) to provide 13 $\mathrm{mg}(100 \%)$ of MFZ $9-17$ as a red solid. MALDI-TOF MS calculated for $\mathrm{C}_{48} \mathrm{H}_{59} \mathrm{~N}_{4} \mathrm{Cl}_{2} \mathrm{O}_{9} \mathrm{~S}_{2}\left([\mathrm{M}+\mathrm{H}]^{+}\right)$was as follows: 969.31 ; found: 969.30 . MFZ 9-18 was prepared from (-)- $N$-(2-aminoethyl)-2 $\beta$-carbomethoxy- $3 \beta$ (3.4-dichlorophenyl)-tropane (Cha et al., 2005) (10.3 mg, $28.9 \mu \mathrm{mol})$ and Oregon Green 488-X, $N$-succinimidyl ester $(15 \mathrm{mg}, 24.09 \mu \mathrm{mol})$ by the same procedure as described for MFZ 9-17 in quantitative yield as an orange solid. MALDI-TOF MS calculated for $\mathrm{C}_{44} \mathrm{H}_{41} \mathrm{~N}_{3} \mathrm{Cl}_{2} \mathrm{~F}_{2} \mathrm{O}_{9}$ $\left([\mathrm{M}+\mathrm{H}]^{+}\right)$was as follows: 864.22 ; found: 864.23.

Molecular biology. A synthetic gene encoding the human DAT (hDAT) in the bicistronic vector pCIHygro and hDAT tagged at the $\mathrm{N}$ terminus with enhanced green fluorescent protein (EGFP-hDAT) were kindly provided by Dr. Jonathan A. Javitch, Columbia University (New York, NY) (Rees et al., 1996; Saunders et al., 2000). The cDNAs encoding dynamin and the dominant-negative dynamin mutant K44A in pFUGW-IRES-GFP were kind gifts from Dr. Rosalind A. Segal (Harvard Medical School, Boston, MA) (Zhou et al., 2007). pHsSynXW EGFP-Rab5a was generated by excising the cDNA encoding EGFP-Rab5A from pEGFP Rab5A (a kind gift from Dr. Katherine W. Roche, National Institute of Neurological Disorders and Stroke, Bethesda, MD) (Lavezzari et al., 2004) using Agel and HpaI restriction sites followed by insertion into the lentiviral transfer vector $\mathrm{pHsCXW}$ (Leander Johansen et al., 2005). The CMV promoter was replaced with the promoter of synapsin to ensure selective neuronal expression (Dittgen et al., 2004).

Cell culture and transfection. Human embryonic kidney cells (HEK) 293 were grown in DMEM with GlutaMax (L-alanyl-L-glutamine), $10 \%$ fetal calf serum, and $0.01 \mathrm{mg} / \mathrm{ml}$ gentamicin (all reagents from Invitrogen) at $37^{\circ} \mathrm{C}$ in a humidified 5\% $\mathrm{CO}_{2}$ atmosphere. For stable expression of hDAT and EGFP-hDAT, HEK293 cells were seeded in $100 \mathrm{~mm}$ tissue culture plates, grown to $\sim 30 \%$ confluence, and subsequently transfected with $2 \mu \mathrm{g}$ of the pCIHygro constructs using Lipofectamine according to the instructions from the manufacturer (Invitrogen). A stably transfected pool was selected with $200 \mu \mathrm{g} / \mathrm{ml}$ hygromycin (Invitrogen) starting $2 \mathrm{~d}$ after transfection and continuing until control cells were dead, after which selection pressure were maintained with 100 $\mu \mathrm{g} / \mathrm{ml}$ hygromycin. For transient expression of hDAT, HEK293 cells $\left(3 \times 10^{6}\right.$ cells) were seeded in $75 \mathrm{~cm}^{2}$ flasks. The cells were transfected the day after seeding with $3 \mu \mathrm{g}$ of DNA and $9 \mu \mathrm{l}$ of Lipofectamine 2000 reagent according to the manufacturer's instructions.

Preparation and culturing of neurons. Postnatally derived rat midbrain dopaminergic neurons were isolated and grown modified from (Rayport et al., 1992). Briefly, the cultures were obtained from the ventral midbrain of 1- to 3-d-old pups. The dissected tissue sample was digested in a papain solution for $\sim 30 \mathrm{~min}$ at $37^{\circ} \mathrm{C}$ while slowly superfused with a mixture of $95 \% \mathrm{O}_{2}$ and $5 \% \mathrm{CO}_{2}$. The digested tissue was carefully triturated into single cells using increasingly smaller pipette tips. The cells were centrifuged at $500 \times g$ for $5 \mathrm{~min}$ and resuspended in warm SF1C consisting of 50\% MEM (Modified Eagle's Medium), 40\% DMEM, and $10 \%$ F-12 Ham's nutrient mixture (all from Invitrogen) supplemented with bovine serum albumin $(2.5 \mathrm{mg} / \mathrm{ml})$, D-glucose $(0.35 \%)$, glutamine $(0.5 \mathrm{~mm}), 1 \%$ heat-inactivated calf serum (Invitrogen), kynurenic acid (5 $\mathrm{mm}$ ), penicillin, streptomycin, liquid catalase $(0.05 \%)$, and DiPorzio (di Porzio et al., 1980) (containing insulin, transferrin, superoxide dismutase, progesterone, cortisol, $\mathrm{Na}_{2} \mathrm{SeO}_{3}$, and T3). The neurons were plated on a monolayer of glial cells grown on coverslips. The cells were allowed to settle for $\sim 2 \mathrm{~h}$ before addition of GDNF (Millipore Bioscience Research Reagents) (10 ng/ml). The next day 5 -fluorodeoxyuridine was added to inhibit growth of glial cells. The cultures were used for experiments after $4-16 \mathrm{~d}$ in vitro (DIV).

Lentivirus production and transduction. Lentiviral vectors were produced according to procedures modified from Naldini et al. (1996b). HEK293T packaging cells (ATCC number CRL-11268) were plated on poly-ornithine-coated $175 \mathrm{~cm}^{2}$ flasks and transiently triple transfected with the following: (1) $18 \mu \mathrm{g}$ of a packaging plasmid encoding viral structure proteins (pBR $\Delta 8.91$ ) (Zufferey et al., 1997); (2) $12 \mu \mathrm{g}$ of an envelope plasmid encoding the envelope protein VSV-G (pMD.G) (Naldini et al., 1996a); and (3) $18 \mu \mathrm{g}$ of the transfer plasmid containing the gene of interest (pFUGW-IRES-GFP Dynamin, pFUGW-IRES-GFP Dynamin K44A, pHsSynXW CKAR, or pHsSynXW EGFP-Rab5a). Transfection was performed in DMEM (Invitrogen) supplemented with 10\% FBS (Invitrogen) using calcium phosphate precipitation. Medium was replaced with fresh medium after $5 \mathrm{~h}$. Approximately 48 and $72 \mathrm{~h}$ after transfection, media containing lentivirus was collected, centrifuged at $900 \times g$ for $5 \mathrm{~min}$ to remove cellular debris, filtered through a $0.45 \mu \mathrm{m}$ filter, and concentrated by ultracentrifugation at $50,000 \times g$ for $1.5 \mathrm{~h}$ at $4^{\circ} \mathrm{C}$. The virus-containing pellet was resuspended in MEM (Sigma) at 
$1 / 280$ of the original volume and stored in aliquots at $-80^{\circ} \mathrm{C}$. The neuronal cultures were incubated with concentrated lentivirus on days 2-3 in vitro and experiments were performed $6-8 \mathrm{~d}$ after infection.

Immunocytochemistry. Dopaminergic neurons, grown on a monolayer of glial cells on coverslips, were incubated with $10 \mathrm{~nm}$ JHC 1-64 in buffer 1 (25 mM HEPES, pH 7.4, with $130 \mathrm{~mm} \mathrm{NaCl}, 5.4 \mathrm{~mm} \mathrm{KCl}, 1.2 \mathrm{~mm} \mathrm{CaCl}, 1.2$ $\mathrm{mM} \mathrm{MgSO}_{4}, 1 \mathrm{~mm}$ L-ascorbic acid, $5 \mathrm{~mm}$ D-glucose) for $20 \mathrm{~min}$ at room temperature (RT). Subsequently, the cells were washed and fixed in 3.7\% formaldehyde in PBS for $20 \mathrm{~min}$ at $4^{\circ} \mathrm{C}$ before the specimen was permeabilized and blocked in blocking/permeabilization buffer $(0.1 \%$ digitonin, $1 \%$ bovine serum albu$\mathrm{min}$, and $5 \%$ goat serum in PBS). The neurons were stained with either a rat anti-DAT antibody (1:1000; MAB369; Millipore Bioscience Research Reagents), rabbit anti-VMAT2 (vesicular monoamine transporter 2) antibody (1:1000; Peel-Freez Biologicals), or a rabbit anti-TH (tyrosine hydroxylase) antibody (1:1000; Affinity Bioreagents) in blocking/permeabilization buffer for $1 \mathrm{~h}$, washed 3 times in PBS, and incubated for $30 \mathrm{~min}$ with either Alexa Fluor 488 goat anti-rat or goat anti-rabbit antibody (1:500; Invitrogen). Finally, the specimens were mounted on glass slides with SlowFade Antifade (Invitrogen). The specimens were imaged using a Zeiss LSM 510 confocal laser-scanning station with an oil-immersion $63 \times 1.4$ NA objective (Zeiss). JHC 1-64 was visualized using a $543 \mathrm{~nm}$ HeNe laser line and a $585 \mathrm{~nm}$ long-pass filter, whereas Alexa Fluor 488 was excited with the $488 \mathrm{~nm}$ laser line from an argon-krypton laser and the emitted light was detected using a $505-550 \mathrm{~nm}$ bandpass filter.

Live cell imaging. HEK293 cells stably expressing either hDAT or EGFP-tagged hDAT were grown in DMEM plus 10\% FCS in poly-Lornithine-treated 8-well LabTek Chambers. On the day of the experiment, the cells were incubated with the indicated fluorescent cocaine analogs in PBS with $5 \mathrm{~mm}$ glucose for designated time periods. After incubation, the living cells were imaged at RT using a Zeiss LSM 510 with a $63 \times$ NA 1.4 objective (Zeiss). The compounds JHC 1-64 and MFZ 9-17 were visualized using a $543 \mathrm{~nm}$ HeNe laser line and a $585 \mathrm{~nm}$ long-pass filter, whereas MFZ 9-18 and EGFP were detected with a $488 \mathrm{~nm}$ argon-krypton laser line and a $505-530 \mathrm{~nm}$ bandpass filter.

For imaging in dopaminergic neurons, ventral midbrain neurons grown in 2-well LabTek chambers on a glial monolayer for 4-16 DIV were used for all live neuron imaging studies. The neurons were incubated with $5 \mathrm{~nm}$ JHC $1-64$ or $10 \mathrm{~nm}$ MFZ 9-18 in buffer $1(25 \mathrm{~mm}$ HEPES, pH 7.4, with $130 \mathrm{~mm} \mathrm{NaCl}, 5.4 \mathrm{~mm} \mathrm{KCl}, 1.2 \mathrm{mM} \mathrm{CaCl}_{2}, 1.2 \mathrm{~mm}$ $\mathrm{MgSO}_{4}, 1 \mathrm{~mm} \mathrm{~L}$-ascorbic acid, $5 \mathrm{~mm}$ D-glucose) for $20 \mathrm{~min}$ at room temperature. As controls for JHC 1-64's DAT specificity in neurons, the cultures were either preincubated with $1 \mathrm{~mm}$ dopamine, $1 \mu \mathrm{M}$ mazindol, $10 \mu \mathrm{M}$ desmethylimipramine, or $1 \mu \mathrm{M}$ citalopram in uptake buffer for 15 min, before addition of $5 \mathrm{nM} \mathrm{JHC} \mathrm{1-64} \mathrm{to} \mathrm{the} \mathrm{buffer} \mathrm{and} \mathrm{incubation} \mathrm{for}$ $20 \mathrm{~min}$ at RT. The cells were imaged as described for the HEK293 live cell experiments.

To detect internalization in midbrain dopaminergic neurons, the cultures were incubated with $5 \mathrm{nM} \mathrm{JHC} 1-64$ for $30 \mathrm{~min}$ at $4^{\circ} \mathrm{C}$, before the buffer was removed and replaced with $37^{\circ} \mathrm{C}$ warm uptake buffer (containing vehicle, $450 \mathrm{~mm}$ sucrose, or $1 \mu \mathrm{M}$ PMA) and incubated for 30 or
$>585 \mathrm{~nm}$

\section{Overlay}
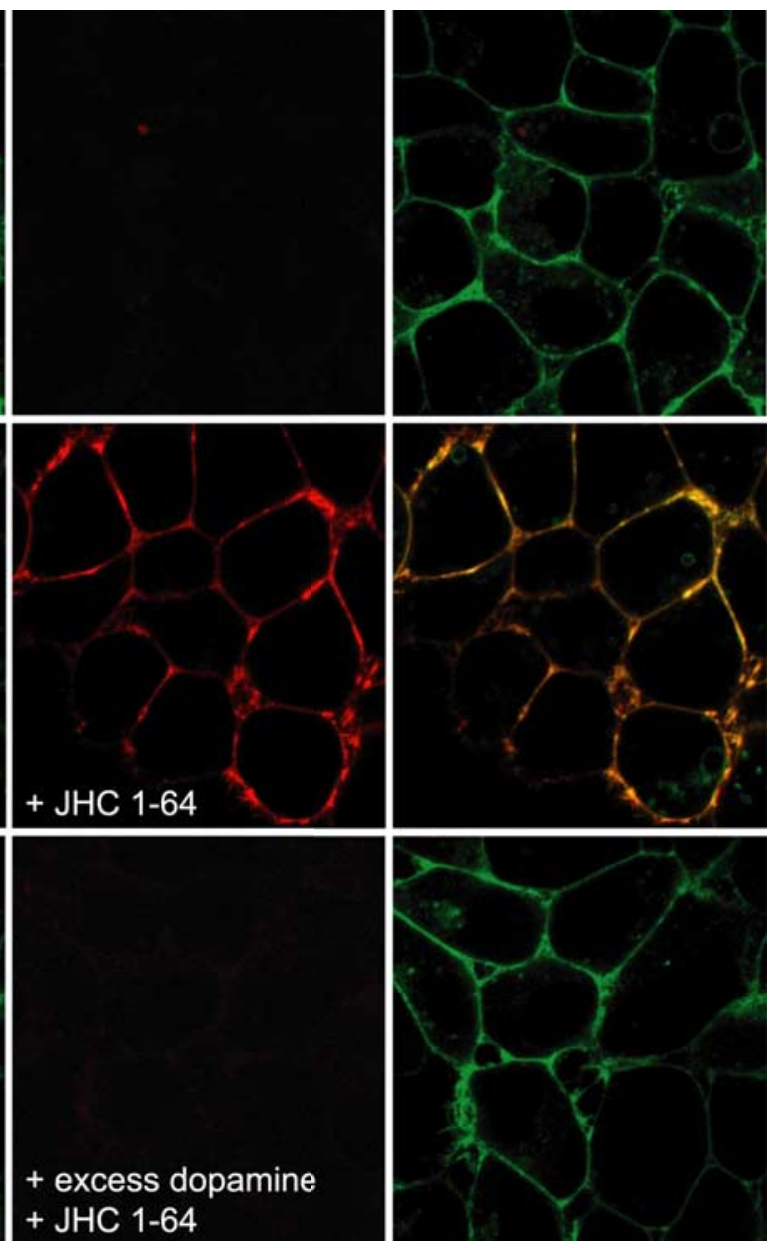

Figure 2. Specific labeling of EGFP-DAT with the fluorescent cocaine analog JHC 1-64. Top, Live HEK293 cells stably expressing EGFP-DAT without JHC 1-64 preincubation. Middle, Live HEK293 cells stably expressing EGFP-DAT preincubated with $5 \mathrm{~nm} \mathrm{JHC}$ 1-64 for 20 min at RT. Bottom, Live HEK293 cells stably expressing EGFP-DAT preincubated with $1 \mathrm{~mm}$ dopamine for 15 min 505-530 nm bandpass filter for recording of fluorescence. For visualization of JHC 1-64 we used a $543 \mathrm{~nm}$ HeNe laser for excitation and $a>585 \mathrm{~nm}$ long-pass filter for recording of fluorescence. The shown images are representative of at least five similar experiments with the same result.

$60 \mathrm{~min}$ at $37^{\circ} \mathrm{C}$ (or $4^{\circ} \mathrm{C}$ for a temperature control). For the transferrin cointernalization experiments we used Alexa Fluor 488-conjugated transferrin (1:100; Invitrogen). After incubation the neurons were imaged at room temperature with same settings as described for the HEK293 cells and the distribution of JHC 1-64 on the neurons were analyzed with a $Z$-scan.

Time lapses were performed on midbrain dopaminergic neurons grown in LabTek chambers and incubated with 5 nM JHC 1-64 in buffer 1 for up to $1 \mathrm{~h}$ at $37^{\circ} \mathrm{C}$ to allow labeling of the DAT and subsequent constitutive internalization of the JHC 1-64/DAT complex. Next, the cells were washed once with buffer 1 and analyzed on the Zeiss LSM510 station with a heated stage kept at $37^{\circ} \mathrm{C}$. The JHC 1-64/DAT complex was visualized by excitation with a $543 \mathrm{~nm} \mathrm{HeNe}$ laser line. Pictures are an average of 2 line scans. Time series were obtained with 300 pictures in 20 min.

Fluorescence recovery after photobleaching. Cultures of midbrain dopaminergic neurons were labeled with $5 \mathrm{nM} \mathrm{JHC} \mathrm{1-64} \mathrm{for} 20 \mathrm{~min}$ followed by washing the cells in buffer 1 . The neurons were subsequently kept in buffer with $10 \mu \mathrm{M}$ RTI55 during the experiment to avoid any rebinding of JHC 1-64 to DAT. The fluorescence recovery after photobleaching (FRAP) measurements and calculations were performed essentially as described (Adkins et al., 2007). Spot photobleaching using circular regions of interest (ROIs) of $1-3 \mu \mathrm{m}$ in diameter were placed on the neu- 
A $505-530 \mathrm{~nm}$
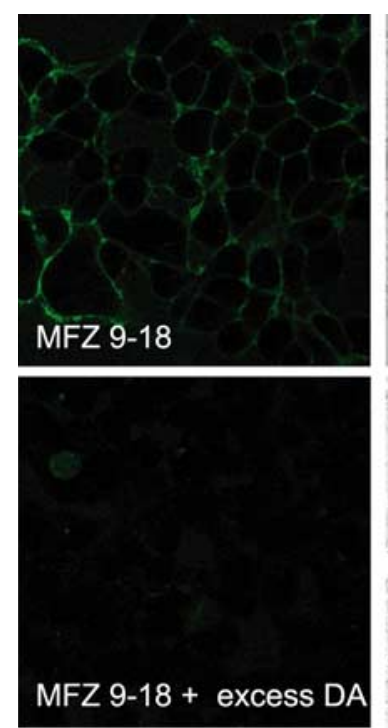

B

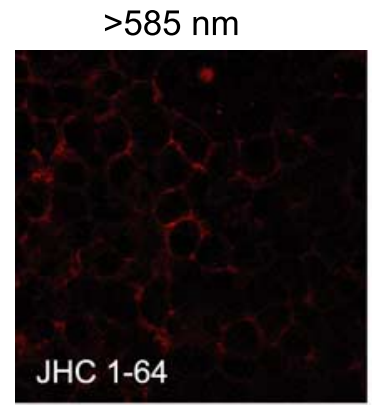

Transmission
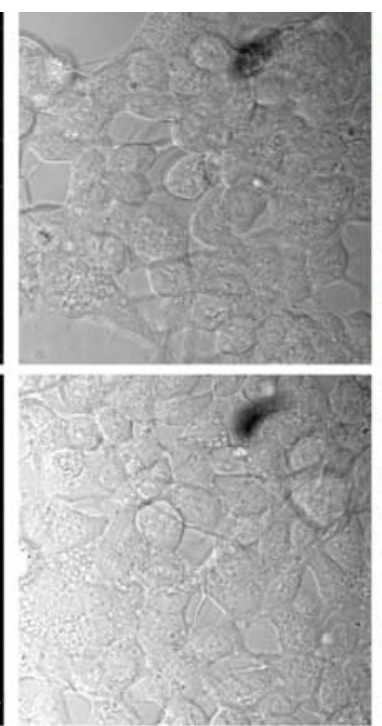

$505-530 \mathrm{~nm}$

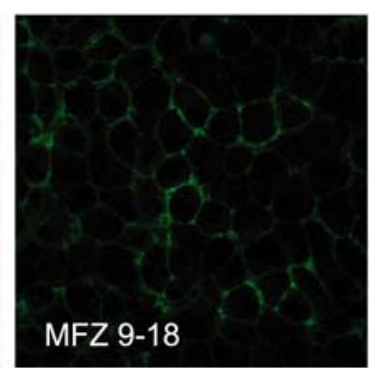

Overlay
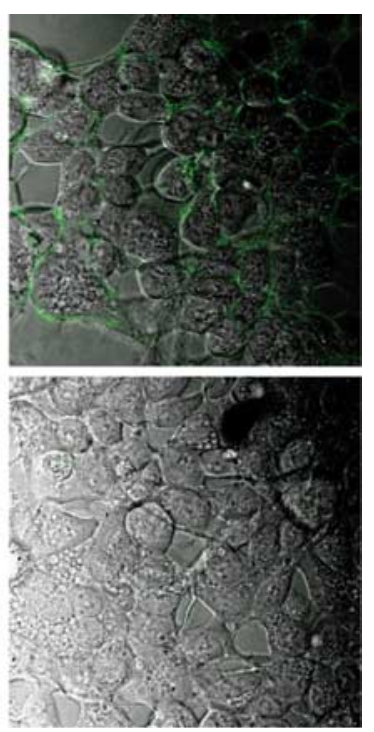

Figure 3. Specific labeling of DAT with the fluorescent cocaine analog MFZ 9-18. $\boldsymbol{A}$, Live HEK293 cells stably expressing DAT preincubated with $10 \mathrm{~nm}$ MFZ 9-18 for $20 \mathrm{~min}$ at RT (top) or with $1 \mathrm{~mm}$ dopamine for 15 min followed by $10 \mathrm{~nm}$ MFZ $9-18$ for 20 min at RT (bottom). MFZ 9-18 was visualized using a $488 \mathrm{~nm}$ argon laser for excitation and a 505-530 nm bandpass filter for recording of fluorescence. $\boldsymbol{B}$, Live HEK293 cells stably expressing DAT preincubated with $10 \mathrm{~nm} \mathrm{MFZ} \mathrm{9-18} \mathrm{and} 5 \mathrm{~nm}$ JHC 1-64 for 20 min at RT. The left panel shows fluorescence in the $>585 \mathrm{~nm}$ channel, the middle panel shows fluorescence in the $505-530 \mathrm{~nm}$ channel, and the right panel shows overlay of the two channels. The shown images are representative of three similar experiments with the same result.

ronal extensions or boutons of the selected neurons, followed by bleaching of the region with the $488 \mathrm{~nm}$ laser line at $100 \%$ output for $\sim 700 \mathrm{~ms}$ to obtain $30-70 \%$ bleaching compared with prebleach image. The pinhole was kept fully open to ensure complete bleaching through the cell. The transmission intensity was no higher than $1 \%$, and the bleaching of the sample due to imaging was negligible according to experiments on fixed cells (data not shown). Images were obtained every $500 \mathrm{~ms}$ for an average of 1 min using the $543 \mathrm{~nm}$ laser line and a $585 \mathrm{~nm}$ long-pass filter. Measurements up to $5 \mathrm{~min}$ were also performed, with no change in diffusion time or mobile fraction observable after the first minute. Images were processed with Photoshop 6.0 (Adobe), and recovery curves were calculated using nonlinear least-squares fits in ORIGIN 5.0 (OriginLab) set to the general equation for FRAP as by (Yguerabide et al., 1982). The diffusion coefficient was determined using the following equation:

$$
D=\omega_{1}^{2} / 4 \tau_{\mathrm{D}}
$$

where $\omega$ is radius of the ROI set in the Zeiss program, and the $\tau_{\mathrm{D}}$ is determined from the fit of the recovery curve. Because the thickness of the cell was less than the bleached volume in the $z$ direction, Equation 1 was used to determine diffusion coefficients. All measurements were performed at $22^{\circ} \mathrm{C}$.
Dopamine uptake in neurons. The media was removed from midbrain neurons grown on a glial monolayer in 24-well plates (13-15 DIV) and buffer 1 , containing $1 \mu \mathrm{M}$ PMA, $1 \mu \mathrm{M}$ staurosporine, $1 \mu \mathrm{M}$ GF109203X, or vehicle was added before incubation for $30 \mathrm{~min}$ at $37^{\circ} \mathrm{C}$. The incubation was terminated by aspirating the buffer followed by addition of $400 \mu \mathrm{l}$ of buffer 1 containing $1 \mu \mathrm{M}$ the catechol-Omethyltransferase inhibitor Ro 41-0960 (Sigma) and $100 \mu \mathrm{M}$ pargyline (Sigma). Subsequently, $50 \mu \mathrm{l}$ of vehicle or $10 \mu \mathrm{m}$ cocaine (final concentration) for determination of nonspecific binding was added before addition of either $\sim 100 \mathrm{~nm}\left[{ }^{3} \mathrm{H}\right]$ dopamine $\left[2,5,6-\left({ }^{3} \mathrm{H}\right)\right.$ dopamine (7-21 Ci/mmol) (GE Healthcare)] or $\sim 100 \mathrm{~nm}\left[{ }^{3} \mathrm{H}\right]$ dopamine plus $1 \mu \mathrm{M}$ unlabeled in $50 \mu \mathrm{l}$ of buffer 1 . After $3 \mathrm{~min}$ of incubation at RT, the cells were washed twice with $500 \mu \mathrm{l}$ of ice-cold buffer 1 , lysed in $250 \mu \mathrm{l}$ of $1 \%$ SDS, and left for $1 \mathrm{~h}$ at $37^{\circ} \mathrm{C}$. Nonspecific binding was determined in the presence of $100 \mu \mathrm{M}$ cocaine. All samples were subsequently transferred to 24-well counting plates (PerkinElmer Life Sciences) followed by addition of $500 \mu \mathrm{l}$ of Opti-phase HiSafe 3 scintillation fluid (PerkinElmer Life Sciences). The samples were counted in a Wallac Tri-Lux $\beta$ scintillation counter (PerkinElmer Life Sciences). All determinations were performed in triplicate. $\left[{ }^{3} \mathrm{H}\right.$ ] dopamine uptake experiments in HEK293 cells transiently expressing the hDAT to determine inhibition constants for the fluorescent ligands were done as recently described (Cha et al., 2005).

\section{Results}

Synthesis of fluorescent cocaine ligands We have recently synthesized fluorescent cocaine analogs containing rhodamine as the fluorescent moiety (Cha et al., 2005). Of these, JHC 1-64 showed the highest affinity for the human DAT (hDAT) (Cha et al., 2005). The fluorescent tag was extended from the $\mathrm{N}$-position of $2 \beta$-carbomethoxy$3 \beta$-(3,4-dichlorophenyl)tropane using an ethylamino-linker (Fig. 1). To generate a ligand with a different fluorescent spectrum we coupled an Oregon Green moiety to the tropane nitrogen of the parent compound $2 \beta$-carbomethoxy- $3 \beta-(3,4-$ dichlorophenyl)tropane, using the ethylamino linker to give MFZ 9-18 (Fig. 1). Likewise, to generate a more photostable ligand than JHC 1-64, we coupled a Cy3 moiety to the ethylamino-linked tropane nitrogen of the parent compound to give MFZ 9-17 (supplemental Fig. S1, available at www.jneurosci.org as supplemental material). In this way, all three ligands possessed the identical pharmacophore and only differed in the fluorescent moiety extended from the tropane nitrogen (Fig. 1; supplemental Fig. S1, available at www.jneurosci.org as supplemental material).

To estimate the affinity of the two new ligands for the hDAT we determined the potency by which they inhibited $\left[{ }^{3} \mathrm{H}\right]$ dopamine uptake into COS-7 cells transiently expressing the hDAT. The calculated $K_{\mathrm{I}}$ values were $104 \mathrm{~nm}$ [SE interval $(69.2 ; 156 \mathrm{~nm}), n=$ 3] for MFZ 9-17 and $142 \mathrm{~nm}$ [SE interval (57.5;353 nM), $n=3$ ] for MFZ 9-18. For JHC 1-64, we previously reported a $K_{\mathrm{I}}$ value of $62 \mathrm{~nm}$ based on $\left[{ }^{3} \mathrm{H}\right]$ dopamine uptake inhibition experiments and a value of $18 \mathrm{~nm}$ based on $\left[{ }^{3} \mathrm{H}\right] \mathrm{CFT}$ competition binding 

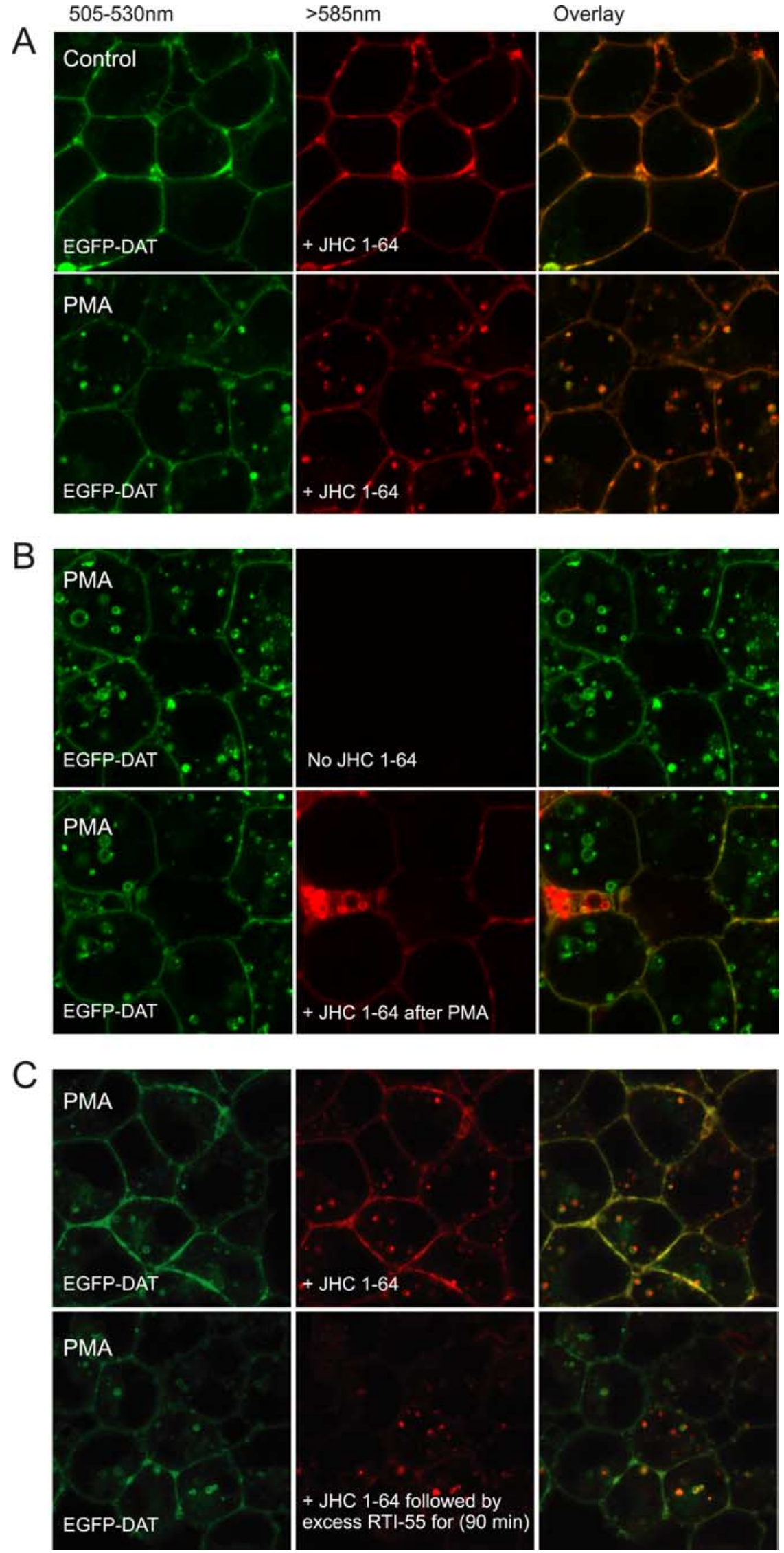

Figure 4. Visualization of DAT internalization in HEK293 cells expressing EGFP-DAT using the fluorescent cocaine analog JHC 1-64. A, PMA promotes internalization of the EGFP-DAT/JHC 1-64 complex in live HEK293 cells stably expressing EGFP-DAT. The cells were incubated in the presence of $5 \mathrm{~nm} \mathrm{JHC} 1-64$ in PBS plus 5 mm glucose at RT for 20 min before incubation in the absence experiments (Cha et al., 2005). Thus, coupling of either Oregon Green or Cy3 instead of rhodamine to the parent compound $2 \beta$-carbomethoxy-3 $\beta$ - $(3,4-$ dichlorophenyl)tropane was also well tolerated by the transporter resulting in two additional high affinity fluorescently tagged DAT ligands.

Visualization of DAT in living HEK293 cells by the fluorescent cocaine analogs To demonstrate DAT labeling by JHC 1-64, we used HEK293 cells stably expressing hDAT with EGFP fused to the $\mathrm{N}$ terminus. The EGFP-hDAT cells were incubated for 20 min with vehicle, $5 \mathrm{~nm} \mathrm{JHC}$ 1-64, or $5 \mathrm{~nm} \mathrm{JHC} \mathrm{1-64} \mathrm{plus} 1 \mathrm{~mm}$ dopamine at RT. The cells were subsequently analyzed by confocal imaging. Recording from the EGFP channel (505-530 nm) showed that EGFP-hDAT was uniformly expressed in the plasma membrane (Fig. 2 ). An essentially identical pattern was observed in the JHC 1-64 channel (>585 $\mathrm{nm}$ ) upon labeling with JHC 1-64 but no fluorescence was observed in the absence of JHC 1-64 and no fluorescence was observed when EGFP-hDAT was blocked with dopamine (Fig. 2). Specific labeling of DAT by JHC 1-64 is further supported by our previous observation that JHC 1-64 only labeled DAT transfected and not nontransfected HEK293 cells (Cha et al., 2005). Together, our data strongly suggest that JHC 1-64 labels DAT with high specificity and signal-to-noise ratio.

DAT could also be specifically labeled with MFZ 9-17 (supplemental Fig. S1,

\section{$\leftarrow$}

(top) or presence of $1 \mu \mathrm{M}$ PMA (bottom) for 30 min at $37^{\circ}$ C. $\boldsymbol{B}$, JHC 1 -64 only labels EGFP-DAT in the plasma membrane and not internalized EGFP-DAT. HEK293 cells stably expressing EGFP-DAT was incubated for $30 \mathrm{~min}$ at $37^{\circ} \mathrm{C}$ in the presence of $1 \mu \mathrm{M}$ PMA to obtain a fraction of internalized EGFP-DAT before labeling for 20 min in the absence (top) or presence of $5 \mathrm{nM} J \mathrm{HC}$ 1-64 at RT. C, JHC 1-64 has a slow off-rate from EGFP-DAT and JHC 1-64 colocalizes with internalized DAT even after 90 min of incubation. HEK293 cells stably expressing EGFP-DAT was incubated with $5 \mathrm{~nm} \mathrm{JHC} \mathrm{1-64} \mathrm{for} 20$ min at RT before incubation for $30 \mathrm{~min}$ at $37^{\circ} \mathrm{C}$. As in $A$, this resulted in robust internalization of the DAT/JHC 1-64 complex (top). Subsequently, an excess of the high-affinity cocaine analog RTI-55 was added $(10 \mu \mathrm{M})$ before incubation for up to $90 \mathrm{~min}$ at $37^{\circ} \mathrm{C}$. JHC 1-64 only slowly dissociated from the cell surface and the dissociation was only visible after $90 \mathrm{~min}$ (bottom). However, even after 90 min of incubation, JHC 1-64 remained colocalized with EGFP-DAT, suggesting JHC 1-64 as a reliable marker for endocytosed DAT. Left panels show fluorescence in the 505-530 nm channel (EGFP), middle panels show fluorescence in the $>585 \mathrm{~nm}$ channel (JHC 1-64), and right panels show overlay of the two channels. The shown images are representative of at least three similar experiments with the same results. 
available at www.jneurosci.org as supplemental material) and MFZ 9-18 (Fig. 3). The Oregon Green label in MFZ 9-18 was visualized with the same settings of the microscope as for EGFP (Fig. 3A), whereas the Cy3 label in MFZ 9-17 was visualized with the same settings as those used for JHC 1-64 (supplemental Fig. S1, available at www.jneurosci.org as supplemental material). For both ligands, we obtained a uniform labeling of the plasma membrane that was completely blocked by an excess of dopamine consistent with specific labeling of DAT. Additionally, simultaneous labeling with the spectrally distinct compounds JHC 1-64 and MFZ 9-18 revealed overlapping pattern as also would be expected if both ligands specifically bound the hDAT (Fig. 3B).

\section{Visualization of DAT internalization}

Activation of PKC by phorbol esters, such as PMA, is known to cause acute internalization of the DAT in heterologous cell systems (Daniels and Amara, 1999; Melikian and Buckley, 1999; Blakely and Bauman, 2000; Granas et al., 2003; Miranda et al., 2007). To investigate whether we could use the fluorescent cocaine analogs to visualize this internalization, we incubated HEK293 cells stably expressing the EGFP-hDAT with $5 \mathrm{~nm} \mathrm{JHC}$ $1-64$ for $20 \mathrm{~min}$ at RT followed by incubation for $30 \mathrm{~min}$ at $37^{\circ} \mathrm{C}$ in the presence or absence of $1 \mu \mathrm{M}$ PMA. While no apparent change in distribution was observed with vehicle, PMA treatment led to the appearance of intracellular fluorescence in vesicular structures both in the EGFP and in the JHC 1-64 channel consistent with internalization of the transporter (Fig. 4A). In another experiment, we treated the cells with PMA before labeling with JHC 1-64. In the EGFP channel we observed, as expected, clear signs of internalization with significant intracellular fluorescence in vesicular structures; however, we did not observe any intracellular fluorescence from JHC 1-64 (Fig. 4 B). This suggests that JHC 1-64 labels DAT at the surface and that in the time frame of the experiment, the compound does not pass the plasma membrane and label intracellularly localized DAT, to any measurable extent.

We also tested whether JHC 1-64 itself would influence DAT trafficking by use of HEK293 cells transfected with a modified hDAT containing an extracellular HA-tag in the second extracellular loop (HA-DAT) (Sorkina et al., 2006). Insertion of this extracellular tag permitted application of an ELISA-based assay to quantify surface expression as well as it permitted application of antibody feeding experiments to assess internalization. According to the ELISA assay, JHC 1-64 did not alter surface expression of HA-DAT (supplemental Fig. S2A, available at www. jneurosci.org as supplemental material). In the antibody feeding experiment, we performed confocal imaging after labeling with JHC 1-64 (supplemental Fig. S2 B, available at www.jneurosci.org as supplemental material), anti-HA antibody (Alexa Fluor 488 conjugated HA.11) (supplemental Fig. S2C, available at www.jneurosci.org as supplemental material), or both JHC 1-64 and conjugated anti-HA antibody (supplemental Fig. S2D, available at www.jneurosci.org as supplemental material). After $60 \mathrm{~min}$, we observed for all three conditions weak intracellular accumulation of JHC 1-64- and HA.11positive vesicles (supplemental Fig. S2 $B-D$, available at www. jneurosci.org as supplemental material). This represents most likely modest constitutive internalization of HA-DAT that is unaffected by JHC 1-64. Note that Chi and Reith (2003) also have reported constitutive internalization of DAT in HEK293 cells; however, they observed that close to $20 \%$ of surface expressed transporter was internalized over an hour, which appears much higher than indicated from our imaging experiments. Most likely, this apparent discrep- ancy results from the use of different methods and/or different expression levels.

\section{Labeling of DAT with JHC 1-64 is reversible but the off-rate is slow}

We also wanted to evaluate the reversibility of the DAT labeling. This was done first by using HEK293 EGFP-hDAT cells that were labeled with JHC 1-64 followed by treatment for $30 \mathrm{~min}$ at $37^{\circ} \mathrm{C}$ with $1 \mu \mathrm{M}$ PMA. The cells were subsequently washed and incubated at $37^{\circ} \mathrm{C}$ in buffer containing $10 \mu \mathrm{M}$ of the nonfluorescent cocaine analog RTI-55. The degree of JHC 1-64 labeling was followed over time and after $90 \mathrm{~min}$ of incubation the fluorescent labeling of the plasma membrane was reduced, consistent with dissociation of JHC 1-64 from the DAT binding pocket (Fig. 4C); however, the dissociation was slow, i.e., the dissociation was barely apparent after $45 \mathrm{~min}$ of incubation (data not shown). Importantly, labeling of internalized transporter was only slightly reduced as reflected by clear colocalization of EGFP and JHC 1-64 fluorescence even after $90 \mathrm{~min}$ of incubation, indicating that $\mathrm{JHC}$ 1-64 is a reliable reporter of endocytosed DAT (Fig. 4C).

To further verify that the slow loss of fluorescence was indeed a product of a slow off-rate for JHC 1-64 from DAT and not a nonspecific membrane partitioning, we measured the ability of JHC $1-64$ to inhibit $\left[{ }^{3} \mathrm{H}\right]$ dopamine uptake in DAT expressing HEK293 cells after washout at various time points to allow dissociation and prevent rebinding of JHC 1-64. The cells were labeled with $100 \mathrm{nM} \mathrm{JHC} \mathrm{1-64,} 500 \mathrm{~nm}$ JHC 1-64, or vehicle for $30 \mathrm{~min}$ before washing and incubation for $0,20,40$, or $60 \mathrm{~min}$ at $37^{\circ} \mathrm{C}$. $\left[{ }^{3} \mathrm{H}\right]$ dopamine uptake was then assayed after two additional washes. After 60 min washout of either 100 or $500 \mathrm{nM} \mathrm{JHC} \mathrm{1-64,}$ $\left[{ }^{3} \mathrm{H}\right]$ dopamine uptake was still markedly blocked and almost unchanged compared with 0 min washout (i.e., $\sim 10 \%$ of vehicle treated for $100 \mathrm{nM} \mathrm{JHC} 1-64$ and $\sim 5 \%$ of vehicle treated for 500 nM JHC 1-64) with only a tendency toward loss of inhibition was seen (supplemental Fig. S3, available at www.jneurosci.org as supplemental material). These data strongly suggest very slow dissociation of JHC 1-64 from DAT and further support that JHC 1-64 can be used as a tool to track DAT molecules in live cells over even an extended period of time.

\section{Visualization of endogenous DAT in live neurons}

We wanted next to see whether we could use the ligands to visualize DAT endogenously expressed in neurons. We prepared postnatal cultures of rat midbrain neurons and assessed DAT expression by labeling with JHC 1-64. Incubation of the cultures

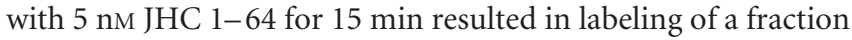
( $\sim 20 \%$ ) but not all neurons in the culture (data not shown). No significant labeling was observed of the glial cell layer on which the postnatal neurons were grown (Fig. $5 A-C$ ). The labeling of the individual neurons indicated a widespread and generally uniform distribution of the DAT in the neurons with plasma membrane staining not only in the neuronal extensions and varicosities but also of the somas (Fig. 5A-C). Coincubation with either an excess of cocaine $(10 \mu \mathrm{M})$ (data not shown), dopamine (1 $\mathrm{mm})$, or the inhibitor mazindol $(1 \mu \mathrm{M})$ blocked all staining except labeling of some irregular rounded structures that likely represented dead or dying cells (Fig. $5 A, B$ ). To validate that we indeed were visualizing endogenously expressed DAT and not SERT or NET, we coincubated with an excess of either the specific SERT inhibitor citalopram or the specific NET inhibitor desmethylimipramine of which neither affected JHC 1-64 staining (Fig. 5B). We also performed stainings with MFZ 9-18 (Fig. 5D), which revealed a labeling pattern very similar to that observed for JHC 
A
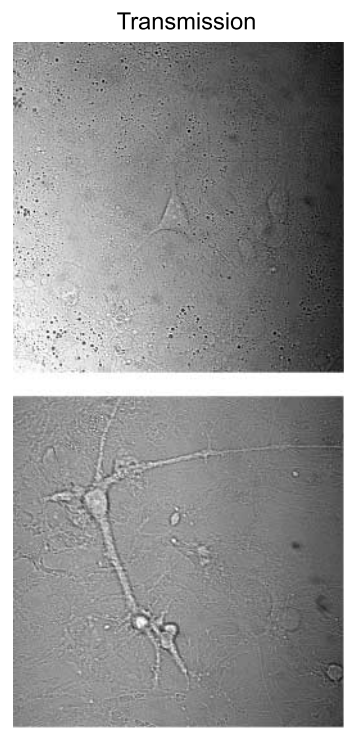

B

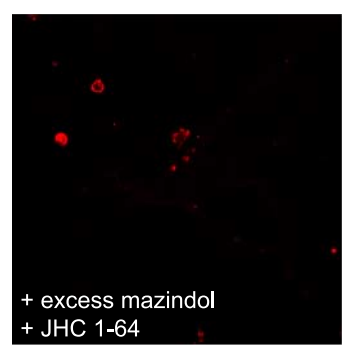

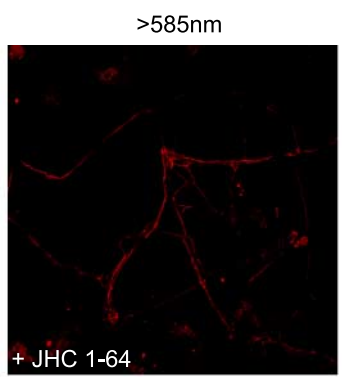
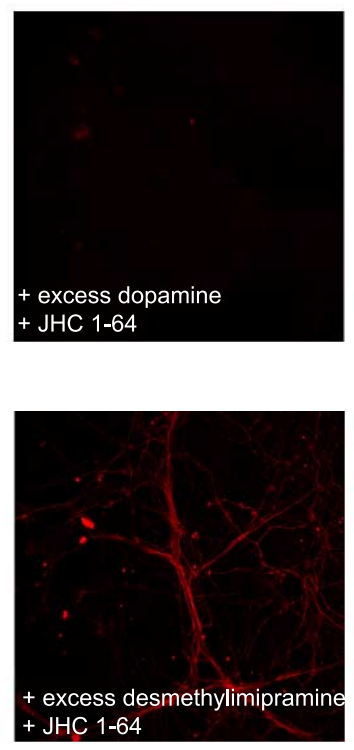
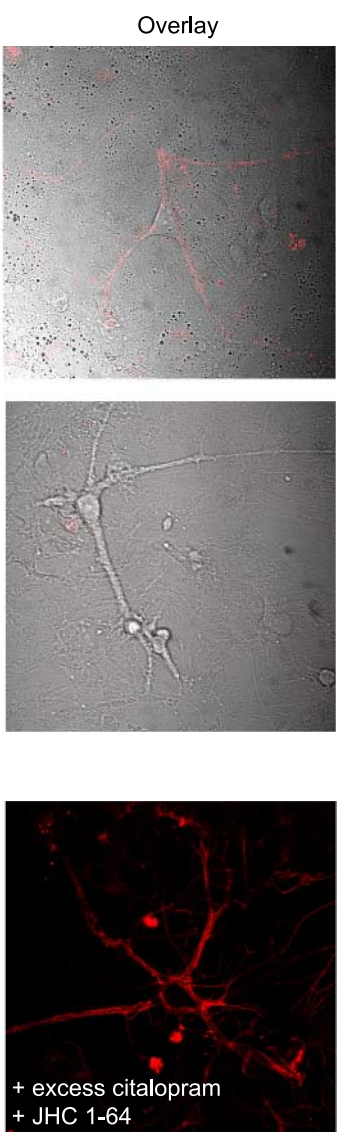

C

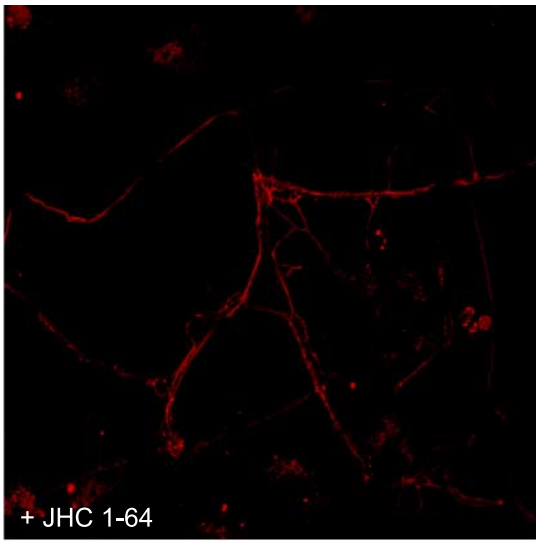

D

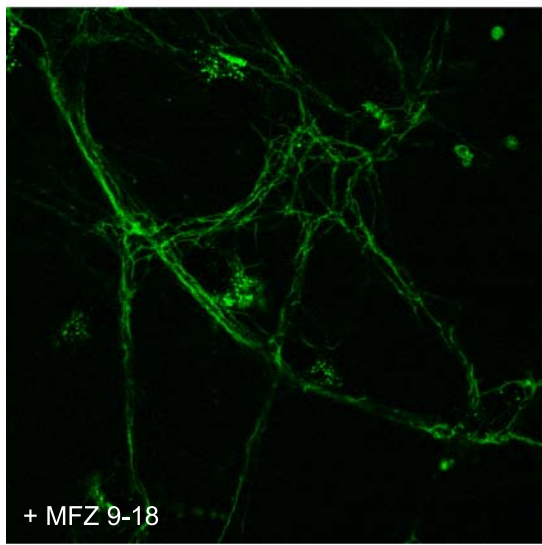

Figure 5. Visualization of endogenously expressed DAT in cultured postnatal midbrain neurons using fluorescent cocaine analogs. A, Labeling with JHC 1-64 is blocked by dopamine. The neuronal cultures were incubated with $5 \mathrm{~nm} \mathrm{JHC} \mathrm{1-64} \mathrm{for} 20 \mathrm{~min}$ (top) or preincubated with $1 \mathrm{~mm}$ dopamine for 15 min before incubation for $20 \mathrm{~min}$ with $5 \mathrm{~nm} \mathrm{JHC} \mathrm{1-64} \mathrm{(bottom).} \mathrm{JHC} \mathrm{1-64} \mathrm{labeled}$ $\sim 20 \%$ of the neurons in the culture. Left panels show transmitted light, middle panels show JHC 1-64 fluorescence, and right panels show overlay. $\boldsymbol{B}$, JHC 1-64 labeling is blocked by the high-affinity DAT inhibitor mazindol but not by the selective SERT inhibitor citalopram or the selective NET inhibitor desmethylimipramine. The neuronal cultures were preincubated for 15 min with either $1 \mu \mathrm{m}$ mazindol (left), $10 \mu \mathrm{m}$ desmethylimipramine (middle), or $1 \mu \mathrm{m}$ citalopram (right) before incubation with $5 \mathrm{~nm}$ JHC 1-64 for 20 min. C, Enlarged picture of the JHC 1-64-labeled neuron shown in $\boldsymbol{A}$. The picture shows a wide and uniform distribution of JHC 1-64 labeling in the plasma membrane of both the soma and the neuronal extensions. D, Visualization of endogenous DAT with MFZ 9-18. The neuronal cultures were incubated with $10 \mathrm{~nm} \mathrm{MFZ} \mathrm{9-18} \mathrm{for} 20$ min. Preincubation with dopamine abolished this labeling (data not shown). The labeling pattern for MFZ $9-18$ strongly resembled that seen for JHC 1-64. JHC 1-64 was visualized by using a $543 \mathrm{~nm}$ HeNe laser for excitation and a $>585 \mathrm{~nm}$ long-pass filter for recording of fluorescence, whereas MFZ 9 -18 was visualized using a $488 \mathrm{~nm}$ argon laser for excitation and a $505-530 \mathrm{~nm}$ bandpass filter for recording of fluorescence. The experiments shown are representative of at least three similar experiments with the same results.

1-64 and like the JHC 1-64, labeling was blocked completely by preincubation with an excess of dopamine (data not shown). Note that when interpreting surface staining of somas and neuronal extensions it is important to be aware of fibers engaging other neurons. This cannot be excluded in, e.g., Figure 5D, whereas, e.g., the overlay of transmission and fluorescence in Figure $5 A$ strongly suggests uniform labeling of the soma and proximal extensions. To address this question further and to enable correlation between labeling and neuronal morphology, the surface distribution of DAT was further studied by performing $Z$-scans through dopaminergic neurons labeled with JHC 1-64. The scans unraveled clear labeling of the soma and a large and uniformly labeled neurite tree (Fig. 6; supplemental Movie 1, available at www.jneurosci.org as supplemental material).

To investigate whether the neurons stained by our fluorescent cocaine analogs possessed the expected features of dopaminergic neurons, we performed a series of immunostainings with antibodies against DAT itself, tyrosine hydroxylase (TH), and the vesicular monoamine transporter-2 (VMAT2), all obligate markers of dopaminergic neurons (Rayport et al., 1992; Nirenberg et al., 1996). The immunostainings were performed subsequent to labeling of the cells with JHC 1-64 (10 nM) for $20 \mathrm{~min}$. In the fixed and permeabilized cells JHC 1-64 staining of the neurons was markedly weaker than that seen in live cells; however, we still saw a similar labeling pattern with labeling of the plasma membrane of the soma, the neuronal extensions and varicosities along these extensions (Fig. 7). Importantly, the labeling was also under these conditions blocked by cocaine and dopamine (data not shown). As compared with live cells, the specific labeling appeared somewhat more punctuate/clustered, which is likely to represent an artifact of the fixation and permeabilization procedure (Fig. 7). Nonetheless, costaining with JHC 1-64 and DAT antibody (MAB369, directed against the intracellular $\mathrm{N}$-terminal) showed almost perfect overlap in the neurons further supporting the specificity of JHC 1-64 labeling (Fig. 7A). Most neurons labeled by JHC 1-64 were also labeled with the antibodies against TH and VMAT2. The TH immunoreactivity was found in the cytoplasm of the soma as well as in the cytoplasm of discrete varicosities and along the neuronal extensions (Fig. $7 B$ ). As a result, the $\mathrm{TH}$ staining did not overlap directly with the plasma membrane staining observed for JHC 1-64 (Fig. 7B). 

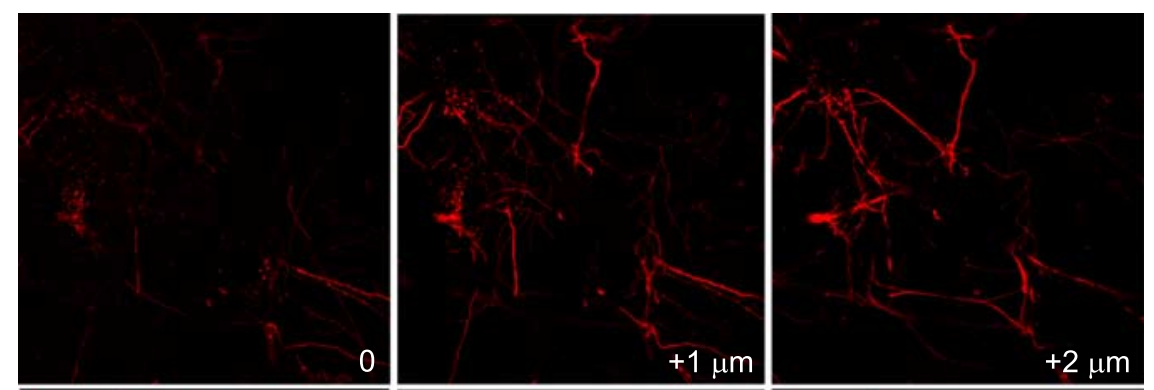

$+3 \mu \mathrm{m}$
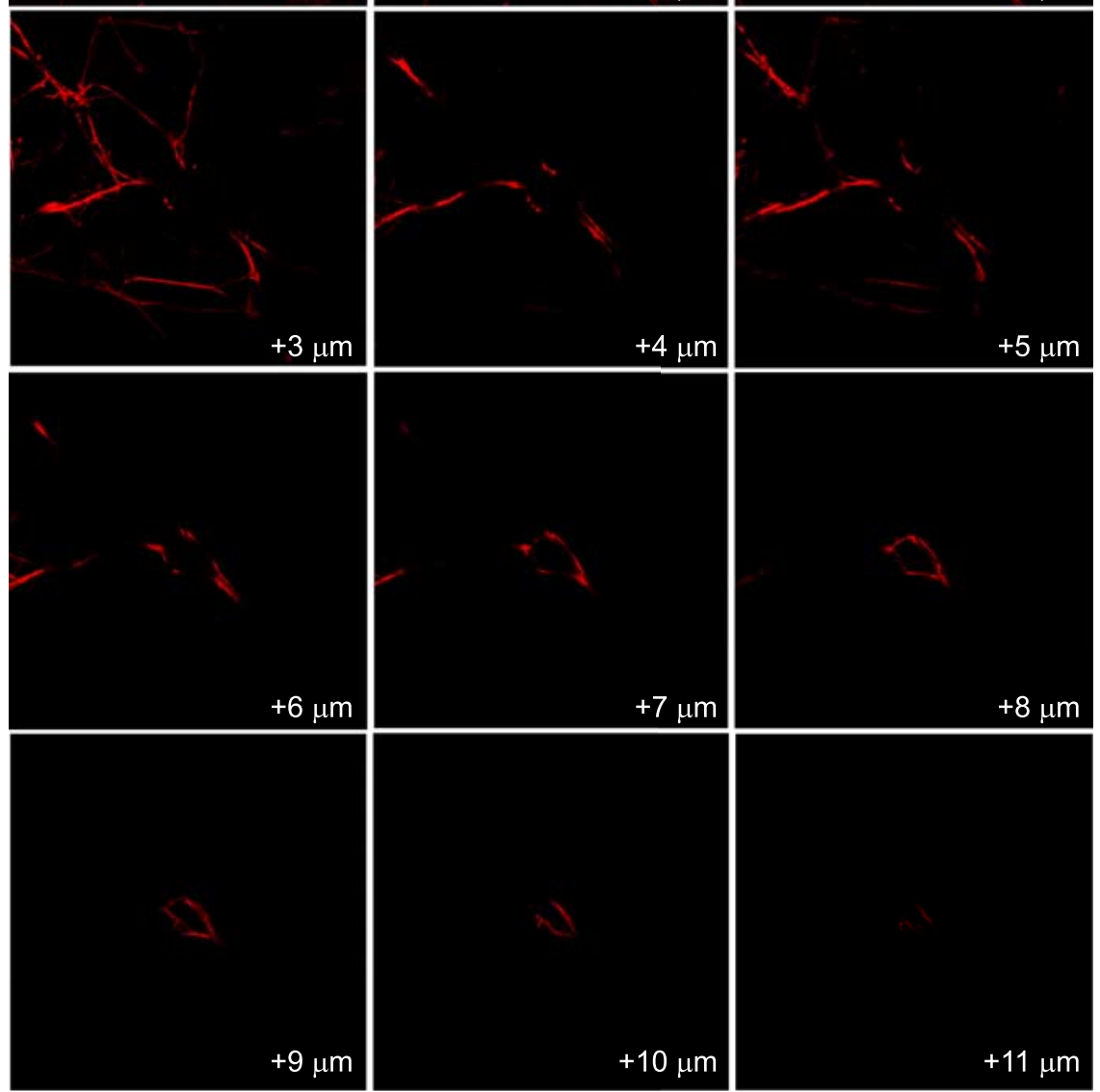

Figure 6. Z-scan of JHC 1-64-labeled dopaminergic neuron. The scan unravels labeling of the soma and a large and generally uniformly labeled neurite tree. The series of pictures shown represent as indicated $1 \mu \mathrm{m}$ sections starting from the surface and ending $11 \mu \mathrm{m}$ above the surface. The neuronal cultures were incubated with $5 \mathrm{~nm} \mathrm{JHC} \mathrm{1-64} \mathrm{for} 20 \mathrm{~min}$ before the analysis was performed. JHC 1-64 was visualized using a $543 \mathrm{~nm}$ HeNe laser for excitation and a $>585 \mathrm{~nm}$ long-pass filter for recording of fluorescence (see also supplemental Movie 1, available at www.jneurosci.org as supplemental material).

While JHC 1-64 staining, and thus DAT, was present not only in the varicosities but also along the neurites as well as in the plasma membrane of the soma, the VMAT2 staining was localized solely to the varicosities (Fig. 7C).

\section{Membrane mobility of the DAT assessed by FRAP}

To assess lateral mobility of the DAT in the plasma membrane of live neurons we performed FRAP (fluorescence recovery after photobleaching) measurements after labeling for $20 \mathrm{~min}$ with 5 nM JHC 1-64. For the bleaching we used the $488 \mathrm{~nm}$ argon laser, a relatively short bleach period $(700 \mathrm{~ms})$, and a circular bleach spot with an average diameter of $1 \mu \mathrm{m}$. The pinhole was kept fully open to ensure complete bleaching through the cell and the bleaching was performed either at the edge of the varicosities or along the neuronal extensions (Fig. $8 \mathrm{~A}$ ). The resulting curves
$+5 \mu \mathrm{m}$

revealed fast recoveries and mobile fractions of larger than $\sim 70 \%$ both in the varicosities and along the neuronal extensions (Fig. $8 \mathrm{~A}$ ) (mobile fraction, varicosities $=$ $72.0 \pm 10.2 \%$; mobile fraction, extensions $=75.3 \pm 7.3 \%, n=20-22)$. The calculated diffusion coefficients were $0.65 \pm 0.06 \times 10^{-9} \mathrm{~cm}^{2} / \mathrm{s}$ in the extensions and $1.14 \pm 0.11 \times 10^{-9} \mathrm{~cm}^{2} / \mathrm{s}, n=$ $30-34)$. These values indicate that the JHC 1-64-occupied transporter is relatively freely moving in the membrane and that the lateral mobility might be even higher in the varicosities than in the extensions.

The mobility of DAT was further investigated by assessing whether DAT preferentially moved unidirectionally or bidirectionally in the neuronal extensions. The neurons were incubated for $20 \mathrm{~min}$ with 5 nM JHC 1-64, after which an extended piece of a neuronal extension (Fig. $8 B$, white box) was bleached with the $488 \mathrm{~nm}$ argon laser for several seconds followed by acquisition of images at appropriate time intervals. As shown in Figure $8 B$, we observed recovery of fluorescence from both sides reaching one another after $\sim 40 \mathrm{~s}$. The recovery appeared to occur with the same rate from either side. This is consistent with no directional movements of surface expressed DAT in the neuronal extensions of cultured dopaminergic neurons.

\section{Assessment of DAT internalization in dopaminergic neurons}

Our data from the transfected HEK293 cells showed that we could assess internalization of the JHC 1-64-labeled transporter by live confocal imaging. To perform similar experiments in the dopaminergic neurons, we first preincubated the neurons with $5 \mathrm{nM}$ JHC 1-64 at $4^{\circ} \mathrm{C}$ followed by incubation for up to $1 \mathrm{~h}$ at $37^{\circ} \mathrm{C}$ in the absence of any stimuli. During this period we observed a marked spontaneous redistribution of the JHC 1-64labeled DAT, as indicated by the appearance of an increasing number of distinct JHC 1-64-positive intracellular vesicles in both the proximal neuronal extensions and in the soma (examples of vesicles indicated by arrows in Fig. $9 A$ ). Under control conditions at $4^{\circ} \mathrm{C}$ over the same time period we did not see any signs of redistribution but only staining of the plasma membrane (Fig. 9A). The redistribution of JHC 1-64labeled DAT was also completely blocked by incubation with hypertonic sucrose, a crude and nonspecific inhibitor of clathrinmediated endocytosis (Heuser and Anderson, 1989; Hansen et al., 1993) (Fig. 9A). Altogether, the data suggest that DAT undergoes marked constitutive internalization in dopaminergic neurons. Interestingly, in DAT expressing HEK293 cells we observed only modest constitutive redistribution upon incubation of the cells at $37^{\circ} \mathrm{C}$ up to $1 \mathrm{~h}$ (supplemental Fig. S4A, available at www.jneurosci.org as supplemental material), indicating a clear dif- 

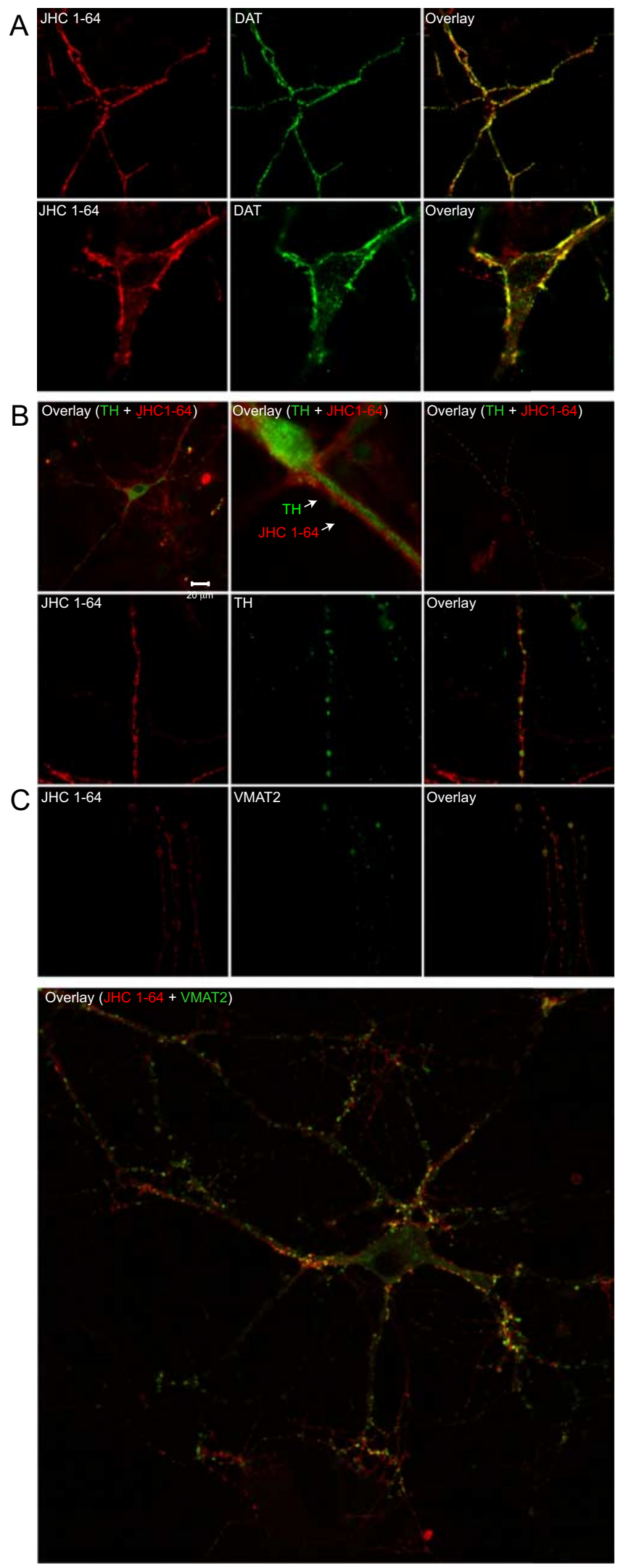

Figure 7. JHC 1-64 labels dopamine transporter (DAT)-positive, tyrosine hydroxylase (TH)positive, and VMAT2-positive neurons. Cultured postnatal midbrain neurons were labeled with

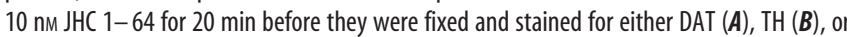
VMAT2 (C). A, Costaining of dopaminergic neuron with JHC 1-64 and rat anti-DAT antibody (MAB369) shown in two different magnifications. DAT immunoreactivity overlaps extensively in the extensions and in the plasma membrane of the soma. $\boldsymbol{B}$, Costaining of dopaminergic ference between natively expressed and heterologously expressed DAT.

We tested next whether PMA affected DAT internalization in the neurons; however, in contrast to our findings in HEK293 cells (supplemental Fig. S4, available at www.jneurosci.org as supplemental material), PMA had no observable effect on internalization of JHC 1-64-labeled DAT in the neurons, hence, JHC 1-64positive intracellular vesicles appeared with a similar rate and to the same degree in the presence of PMA as in the absence of PMA (Fig. 9A). Careful examination of neuronal extensions and varicosities also did not reveal any signs of DAT redistribution in response to PMA. To assess whether the enhanced constitutive internalization seen in the neurons compared with HEK293 cells was the result of generally increased PKC activity, we incubated the cells with the PKC inhibitor staurosporine; however, also this treatment did not alter the observed constitutive DAT internalization (Fig. 9A) even though the same concentration of staurosporine was capable of blocking PMA-induced internalization in HEK293 cells (supplemental Fig. S4 B, available at www.jneurosci.org as supplemental material). We tried in addition the more selective PKC inhibitor GF109203X but due to autofluorescence from this compound we were not able to obtain reliable imaging results (data not shown).

Together, the data suggest that endogenously expressed DAT is not subject to regulation by $\mathrm{PKC}$ in cultured dopaminergic neurons. This is not due to lack of PKC expression since staining with antibody directed against PKC suggested strong expression of the kinase in the DAT-positive neurons (supplemental Fig. S5A, available at www.jneurosci.org as supplemental material). To demonstrate that PKC is not only expressed in the DATpositive neurons but also activated under the same experimental conditions used above, we took advantage of a genetically encoded fluorescence resonance energy transfer (FRET)-based reporter for PKC activity, C kinase activity reporter (CKAR) (Violin et al., 2003; Gallegos et al., 2006). CKAR consists of cyan fluorescent protein (CFP) and yellow fluorescent protein (YFP) tethered together by a substrate peptide specific for PKC and an FHA2 phosphopeptide-binding module. Phosphorylation of CKAR by PKC results in a decrease in the FRET signal between CFP and YFP, which can be measured as an increase in CFP/YFP emission ratio (Violin et al., 2003; Gallegos et al., 2006). First, we transiently expressed CKAR in HEK293 cells and measured the CFP/YFP emission ratio over time. PMA $(1 \mu \mathrm{M})$ caused a rise in the CFP/YFP emission ratio, corresponding to a decrease in the FRET signal and consistent with PMA-mediated activation of PKC (supplemental

$\leftarrow$

neuron with JHC 1-64 and anti-TH antibody. Top row, Three different overlays of JHC 1-64 and TH staining. Although present in the same neuron, the staining did not overlap, i.e., JHC 1-64 primarily stained the plasma membrane, whereas the TH staining appeared intracellular. The rounded strongly stained structure in the left picture is likely to represent a dead or dying cell and, thus, does not represent specific DAT staining by JHC 1-64. Similar rounded structures can also be seen when staining with JHC $1-64$ in the presence of an excess of dopamine or inhibitor (Fig. 5B). Bottom row, JHC 1-64 labeling alone (left), TH staining alone (middle), and overlay (right) corresponding to a neuronal extension with characteristic varicosities. C, Costaining of dopaminergic neuron with JHC 1-64 and anti-VMAT2 antibody. JHC 1-64 labeling alone (left), VMAT2 staining alone (middle), and overlay (right) corresponding to several neuronal extensions. Bottom, Overlay of JHC 1-64 and VMAT2 labeling of an entire dopaminergic neuron. The image illustrates the widespread presence of DAT and its colocalization with VMAT2. JHC 1-64 was visualized by using a $543 \mathrm{~nm}$ HeNe laser for excitation and a $>585 \mathrm{~nm}$ long-pass filter for recording of fluorescence. DAT antibody, TH antibody, and VMAT2 antibody were visualized either using Alexa Fluor 488 goat anti-rat or anti-rabbit antibody. The experiments shown are representative of at least three similar experiments with the same results. 

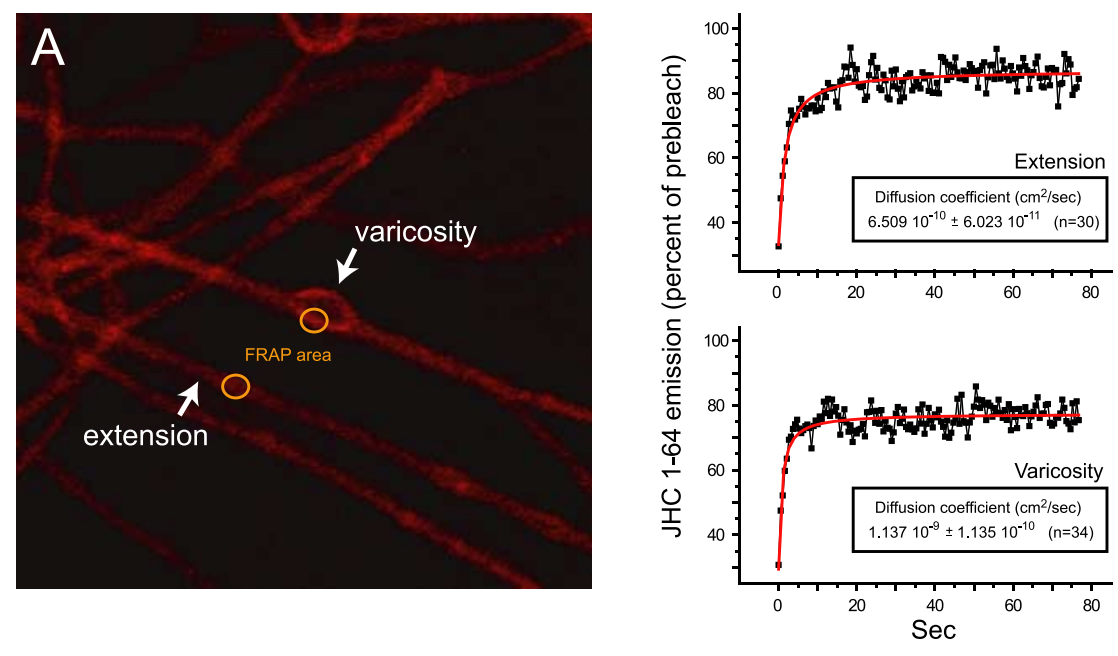

B
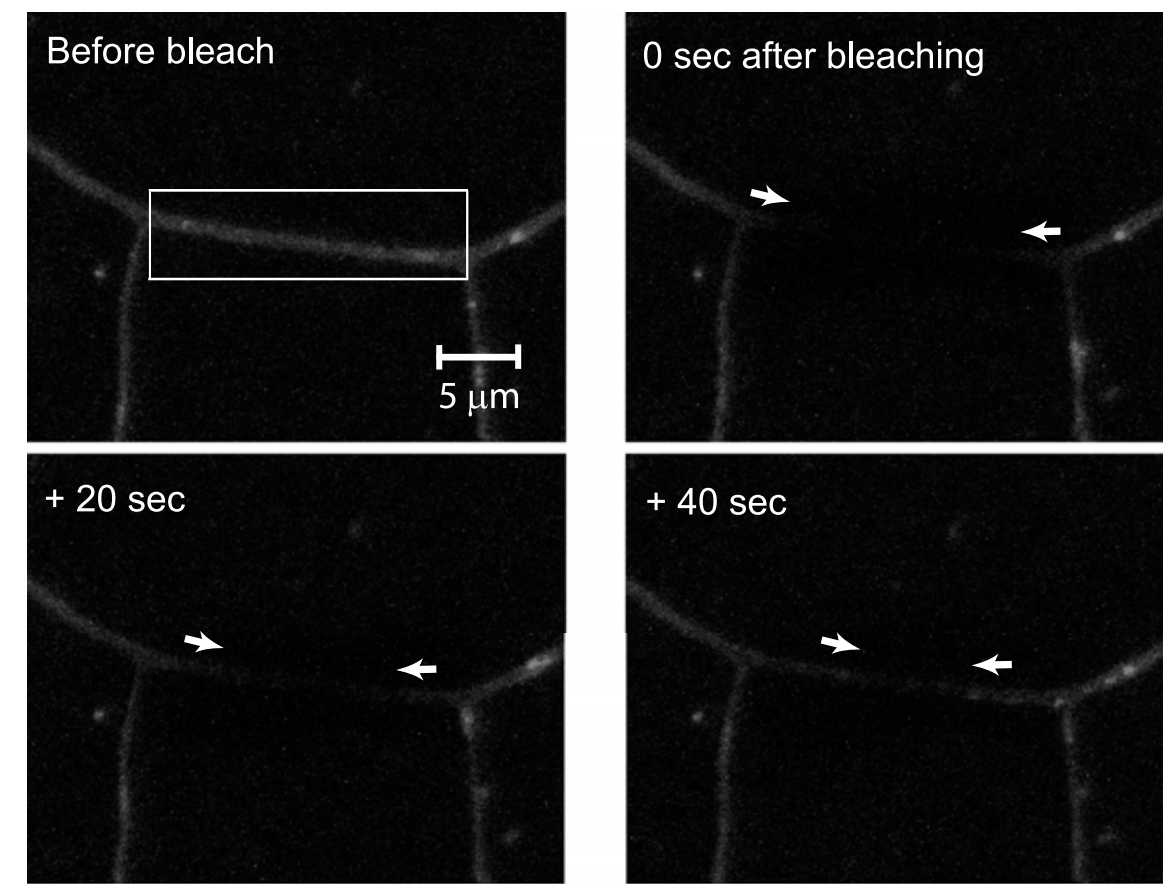

Figure 8. DAT is highly mobile in the plasma membrane of dopaminergic neurons. $A$, FRAP measurements on JHC 1-64labeled DAT in dopaminergic neurons in culture. The neurons were incubated with $5 \mathrm{~nm} \mathrm{JHC} \mathrm{1-64} \mathrm{for} 20$ min at RT, washed in buffer, and kept in buffer with $10 \mu \mathrm{M}$ RTI55 during the experiment to avoid any potential rebinding of JHC $1-64$ to DAT. Left, FRAP was measured at two anatomically distinct locations in the neurons: corresponding to the neuronal extensions and corresponding to the varicosities. Right, Representative FRAP measurements corresponding to an extension and a varicosity. The calculated average diffusion coefficients $(D)$ are indicated. The mobile fractions constituted in the boutons $72.0 \pm 10.2 \%$ and in the extensions $=75.3 \pm 7.3 \%(n=20-22)$ of the labeled transporters. $\boldsymbol{B}$, Illustration of bidirectional lateral movements of DAT along the neuronal extensions. The neurons were labeled as described above with JHC $1-64$ before bleaching the area indicated by the white box using the $488 \mathrm{~nm}$ laser line at $100 \%$ output for $\sim 700$ ms to obtain $30-70 \%$ bleaching compared with prebleach image. Subsequently, the bleached area was monitored and images taken with appropriate time intervals. The experiment shown is representative of at least three similar experiments.

Fig. S5 $B, C$, available at www.jneurosci.org as supplemental material). Next, we expressed CKAR in our midbrain neuronal cultures using lentiviral transduction. The dopaminergic neurons expressing CKAR were identified with JHC 1-64. As shown in supplemental Figure S5C (available at www.jneurosci.org as supplemental material), stimulation with PMA resulted in a significant increase in the CFP/YFP emission ratio, demonstrating PMA-mediated activation of PKC in dopaminergic neurons similar to what was observed in HEK293 cells.
To obtain further support for the absence of PKC regulation in cultured DATpositive neurons, as well as to obtain a quantitative measure, we analyzed the effect of $\mathrm{PKC}$ activation and inhibition on $\left[{ }^{3} \mathrm{H}\right]$ dopamine uptake. Uptake was measured by incubating neurons in culture with $\sim 100 \mathrm{nM}$ $\left[{ }^{3} \mathrm{H}\right]$ dopamine for $3 \mathrm{~min}$, resulting in a specific uptake of $403 \pm 58 \mathrm{pmol} / \mathrm{min} /$ well (mean $\pm \mathrm{SE}, n=4$, nonspecific uptake determined in the presence of $10 \mu \mathrm{M}$ cocaine). As shown in Figure 9B, neither PKC activation with PMA nor PKC inhibition with staurosporine or GF109203 had any detectable effect on the measured uptake. Using a 10 times higher concentration of $\left[{ }^{3} \mathrm{H}\right]$ dopamine did also not reveal any effect of PMA on uptake in the dopaminergic neurons (uptake in response to $1 \mu \mathrm{M}$ PMA was $98.9 \pm 3.9 \%$ of control uptake; mean $\pm \mathrm{SE}, n=3$ ).

To investigate further the constitutive internalization of JHC 1-64-labeled DAT, we used recombinant lentiviral vectors to mediate expression of the dominantnegative dynamin mutation K44A (van der Bliek et al., 1993; Robinson, 1994). To identify transduced cells the vector also encoded GFP separated from dynamin by an internal ribosome entry site (dynamin K44A IRES-GFP). Accordingly, GFPpositive cells indicated efficient lentiviral transduction. First, we performed experiments in DAT expressing HEK293 cells (supplemental Fig. S6, available at www. jneurosci.org as supplemental material). In these cells, transduction with lentivirus encoding dynamin K44A, but not wildtype dynamin, strongly inhibited PMAinduced internalization, in agreement with previous observations for heterologously expressed DAT in MDCK cells (Daniels and Amara, 1999) (supplemental Fig. S6, available at www.jneurosci.org as supplemental material). Next, we transduced our dopaminergic neurons and constitutive internalization of JHC 1-64labeled DAT was assessed as described in Figure $9 A$. A substantial reduction in the amount of constitutively internalized JHC 1-64-labeled DAT was observed in the neurons expressing dynamin K44A, whereas this was not the case in neurons expressing dynamin wild type (Fig. 10A). This suggests that endogenously expressed DAT undergoes constitutive endocytosis via a dynamin-dependent pathway. Note that although the general transduction efficiency of neurons in the culture was high, only a relatively small fraction of the DATpositive neurons was transduced and expressed the dynamin constructs, which underlines the general difficulty in achieving heterologous expression in this type of neurons.

To assess whether JHC 1-64-labeled DAT indeed was constitutively internalized to an endosomal compartment we trans- 
duced the neuronal culture with lentivirus encoding the early endosomal marker Rab5A tagged with EGFP (EGFP-Rab5A) (Zerial and McBride, 2001; Deneka et al., 2003; Lavezzari et al., 2004). As for the dynamin constructs, we observed generally a high transduction efficiency in the culture with rather low transduction efficiency in the dopaminergic neurons. However, in all experiments we were able to identify a number of healthy DAT-positive neurons expressing EGFP-Rab5A. EGFP-Rab5A localized, as would be expected, to vesicular structures in the neurons as well as some nonvesicular cytosolic expression was apparent (Fig. 10B). In constitutive internalization experiments, performed as described in Figure 9A, we observed in the dopaminergic neurons after $60 \mathrm{~min}$ of incubation at $37^{\circ} \mathrm{C}$ several vesicles positive for both JHC 1-64/DAT and EGFPRab5A, supporting constitutive internalization into early endosomes (Fig. 10 B). In some cases, we observed vesicles close to the plasma membrane likely reflecting recent endocytic events (Fig. 10 B, right arrow).

We also performed constitutive internalization experiments upon labeling DAT with JHC 1-64 and the transferrin receptor with Alexa Fluor 488-conjugated transferrin. The transferrin receptor is internalized into early endosomes followed by sorting to recycling endosome (Blanpied et al., 2002). After $30 \mathrm{~min}$, we observed modest JHC 1-64/DAT internalization and marked overlap with transferrin receptor-positive vesicles, again consistent with constitutive internalization of DAT into early endosomes. After $60 \mathrm{~min}$, both JHC 1-64/DAT and transferrin receptor internalization were more pronounced; however, there was a tendency toward less colocalization of JHC 1-64 with transferrin-positive vesicles, which may be indicative of differential sorting of DAT and transferrin receptor (Fig. 10C).

We further explored the constitutively endocytosed JHC 1-64/DAT complex by confocal live imaging. We allowed constitutive internalization to occur by incubating JHC 1-64-labeled dopaminergic neurons for $1 \mathrm{~h}$ of incubation at $37^{\circ} \mathrm{C}$ and subsequently performed time laps with 300 pictures in $20 \mathrm{~min}$ at $37^{\circ} \mathrm{C}$. A representative example of a movie resulting from this protocol is provided in the supplemental material (supplemental Movie 2, available at www.jneurosci.org). The acquired movies revealed multiple JHC 1-64/DAT-positive vesicles undergoing frequent "stepwise" movements. A careful analysis suggested that the vesicles could be divided into at least two major types depending on
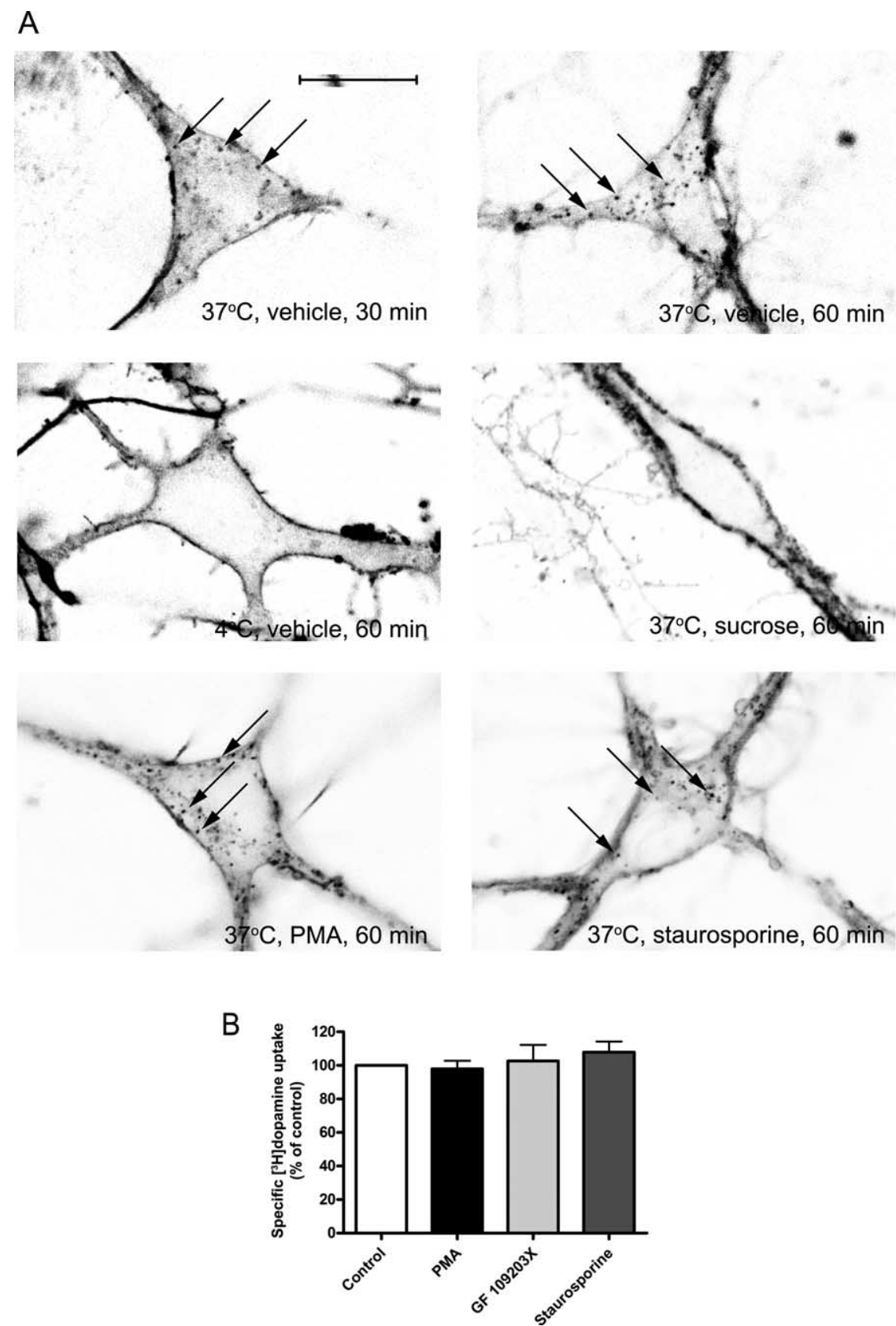

Figure 9. Visualization of constitutive DAT internalization in cultured midbrain dopaminergic neurons (7-10 DIV) using JHC 1-64. A, Images of representative neurons incubated under indicated conditions. JHC 1-64 was visualized by using a $543 \mathrm{~nm}$ HeNe laser for excitation and a $>585 \mathrm{~nm}$ long-pass filter for recording of fluorescence. The images show the fluorescence on a gray scale with darkest pixels representing the largest fluorescence. The neurons were first incubated with 5 nм JHC 1-64 for 30 min at $4^{\circ} \mathrm{C}$ to label surface DAT. Subsequently, the neurons were further incubated at $37^{\circ} \mathrm{C}$ for $30 \mathrm{~min}$ (top left), at $37^{\circ} \mathrm{C}$ for $60 \mathrm{~min}$ (top right), at $4^{\circ} \mathrm{C}$ for $60 \mathrm{~min}$ (middle left), at $37^{\circ} \mathrm{C}$ for $60 \mathrm{~min}$ in the presence of $450 \mathrm{~mm}$ sucrose (middle right), at $37^{\circ} \mathrm{C}$ for $60 \mathrm{~min}$ in the presence of $1 \mu \mathrm{m}$ PMA (bottom left), and at $37^{\circ} \mathrm{C}$ for $60 \mathrm{~min}$ in the presence of $1 \mu \mathrm{m}$ staurosporine (bottom right). The images suggest that the JHC 1-64/DAT complex undergoes temperature-dependent constitutive internalization that is blocked by sucrose. Moreover, and in contrast to what was observed in HEK293 cells, there is no effect on internalization in response to 1 $\mu \mathrm{M}$ PMA. Note that the sucrose treatment slightly alters the appearance of the neuron and makes the membrane looks thicker than in neurons that were not treated with sucrose. Scale bar, $20 \mu \mathrm{m}$. The experiments shown are representative of at least three similar experiments. $\boldsymbol{B},\left[{ }^{3} \mathrm{H}\right]$ dopamine uptake in cultured midbrain neurons was unaffected by PKC activation with $1 \mu \mathrm{M}$ PMA and by PKC inhibition with staurosporine and GF109203X. [ $\left.{ }^{3} \mathrm{H}\right]$ dopamine uptake under control conditions was $403 \pm 58 \mathrm{pmol} / \mathrm{min} /$ well. Data are means $\pm \mathrm{SE}, n=4, p=0.68$, one-sample $t$ test.

their mobility pattern. One type of vesicle was essentially immobilized during the observation period of $10 \mathrm{~min}$ (vesicles indicated by red arrows in Fig. 11). In contrast, other vesicles underwent often rapid movements over rather long distances during 
A
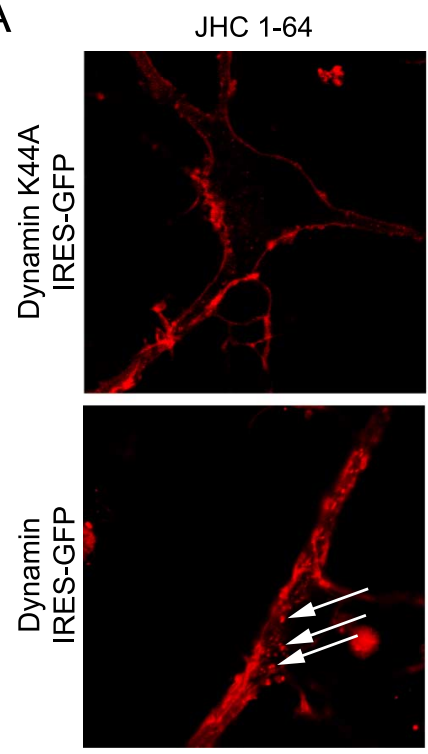

B

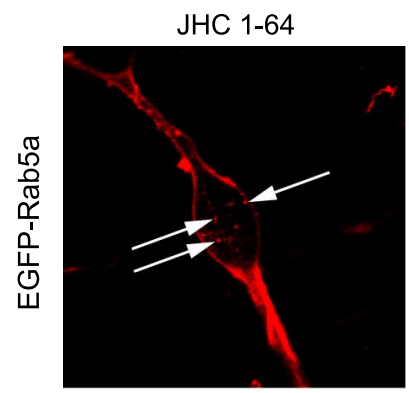

C

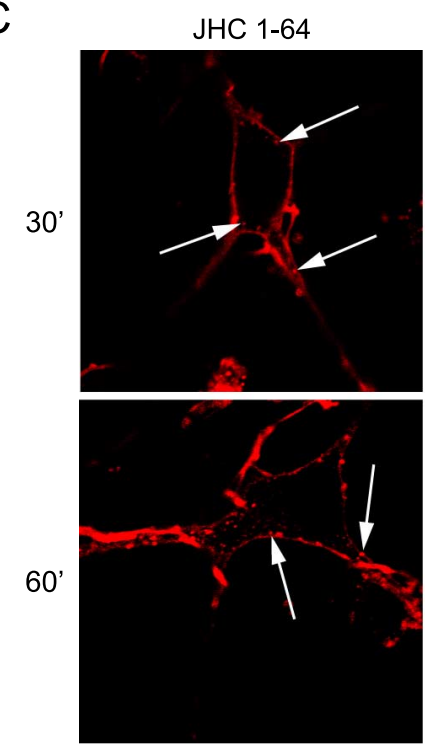

EGFP
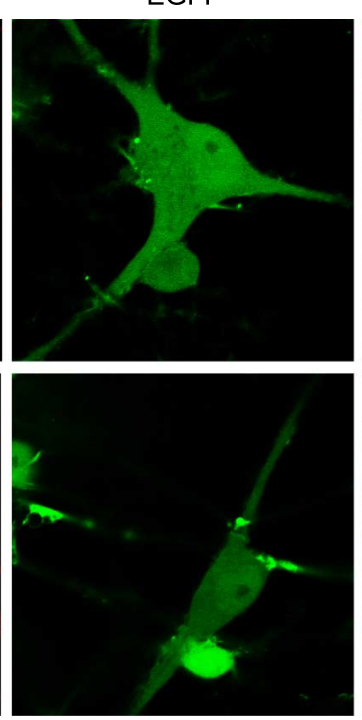

EGFP

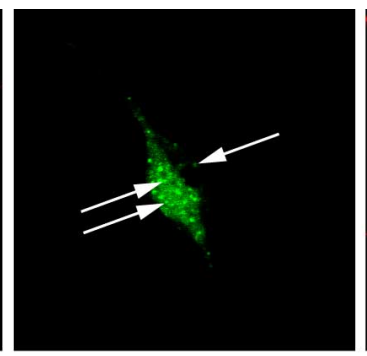

AlexaFluor 488-Tf
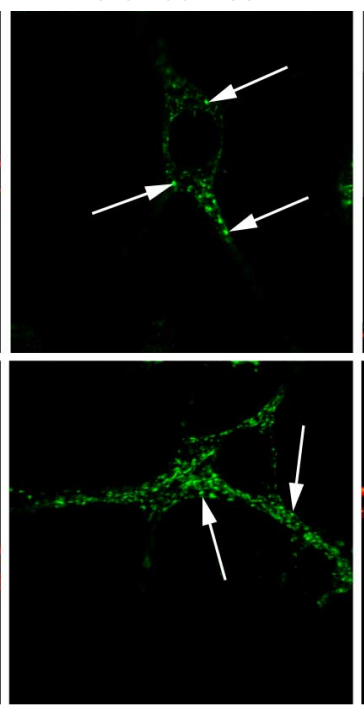
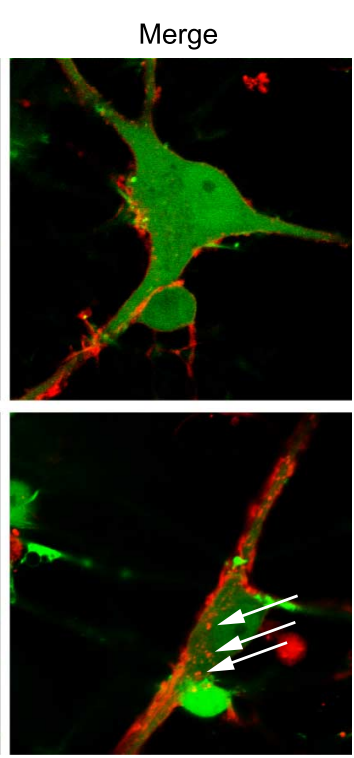

Merge

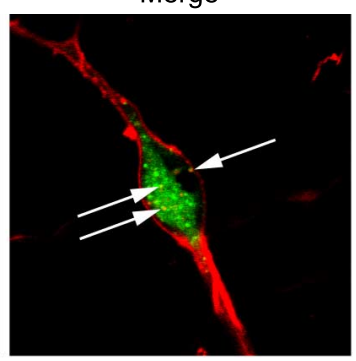

Merge
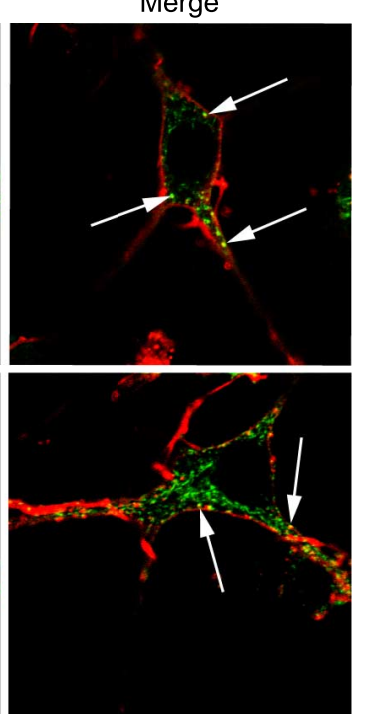

Figure 10. DAT internalizes in dopaminergic neurons into early endosomes in a dynamin-dependent manner. $\boldsymbol{A}$, Constitutive internalization is inhibited by overexpression of the dominant-negative dynamin mutation K44A. The neurons were transduced after 2-3 DIV with lentivirus encoding dominant-negative dynamin K44A or wild-type dynamin, both coupled to GFP expression. The analysis was performed after $8-10$ DIV. The neurons were first incubated with $5 \mathrm{~nm} \mathrm{JHC} 1-64$ for $30 \mathrm{~min}$ at $4^{\circ} \mathrm{C}$ to label surface DAT. Subsequently, the neurons were further incubated for $60 \mathrm{~min}$ at $37^{\circ} \mathrm{C}$ to allow DAT internalization. In neurons expressing dynamin K44A, a substantial reduction in the amount of constitutively internalized DAT was observed, whereas overexpression of wild-type dynamin did not block internalization. In neurons overexpressing wild-type dynamin, selected internalized JHC 1-64positive vesicles are indicated by arrows. B, DAT internalizes into early endosomes. The neurons were transduced after 2-3 DIV with lentivirus encoding the early endosomal marker EGFP-Rab5A and analyzed after 8-10 DIV. Constitutive internalization was allowed as described above. In neurons expressing EGFP-tagged Rab5A, partial overlap between JHC 1-64- and EGFP-Rab5Apositive vesicles was seen. Selected costained vesicles are indicated by arrows. Some costained vesicles were localized close to the plasma membrane, probably indicating recent endocytic events. However, JHC 1-64-positive vesicles that were not EGFP-Rab5A-

the observation period. The movements of these vesicles appeared to occur both toward and away from the soma (see supplemental Movie 2, available at www.jneurosci.org as supplemental material). In conclusion, the data support the existence of an intracellular transporter pool contained in vesicles with distinct mobility patterns, which can be visualized using fluorescently labeled cocaine ligands.

\section{Discussion}

Despite the physiological importance of DAT and its role as drug target, little is known about trafficking of DAT in its native environment and how these processes are regulated. Due to the lack of appropriate tools, the majority of studies has been performed with epitope-tagged transporter in transfected, heterologous cells and, hence, the significance of many observations has not been evaluated in dopaminergic neurons where DAT is endogenously expressed. Here we have addressed this problem by using fluorescently tagged, high-affinity cocaine analogs that permitted direct visualization of endogenously expressed DAT in live dopaminergic neurons.

Previously, we demonstrated synthesis of rhodamine-coupled cocaine analogs with preserved high affinity for the DAT (Cha et al., 2005). Here we introduce two additional high-affinity analogs coupled to two different fluorescent labels, OR Green and $\mathrm{Cy} 3$, each with distinct spectral properties. To validate the usefulness of these analogs, we performed a series experiments in transfected HEK293 cells and, together, the data strongly support that the fluorescently tagged compounds label DAT with high specificity and can be used to track DAT in live cells. For JHC 1-64, we provide evidence for a very slow

\footnotetext{
positive were also observed. Left panels show fluorescence in the $>585 \mathrm{~nm}$ channel (JHC 1-64), middle panels fluorescence in the 505-530 nm channel (GFP or EGFP), and right panels show overlay of the two channels. The experiments shown are representative of $3-5$ independent experiments. $C$, Internalized DAT partially colocalizes with the transferrin receptor. Dopaminergic neurons at 8-10 DIV were incubated for 30 min at $4^{\circ} \mathrm{C}$ with $5 \mathrm{~nm} \mathrm{JHC} 1-64$ to label surface DAT and with AlexaFluor 488-conjugated transferrin to label the transferrin receptor. Subsequently, the neurons were further incubated for $30\left(30^{\prime}\right)$ and $60\left(60^{\prime}\right)$ min at $37^{\circ} \mathrm{C}$ to allow internalization. At 30 min, JHC 1-64/DAT internalization was modest but with marked overlap with transferrin-positive vesicles. After $60 \mathrm{~min}$, a more pronounced JHC 1-64/DAT internalization was observed with partial colocalization with transferrinpositive vesicles. Selected costained vesicles are indicated by arrows. The experiment shown is representative of three independent experiments.
} 

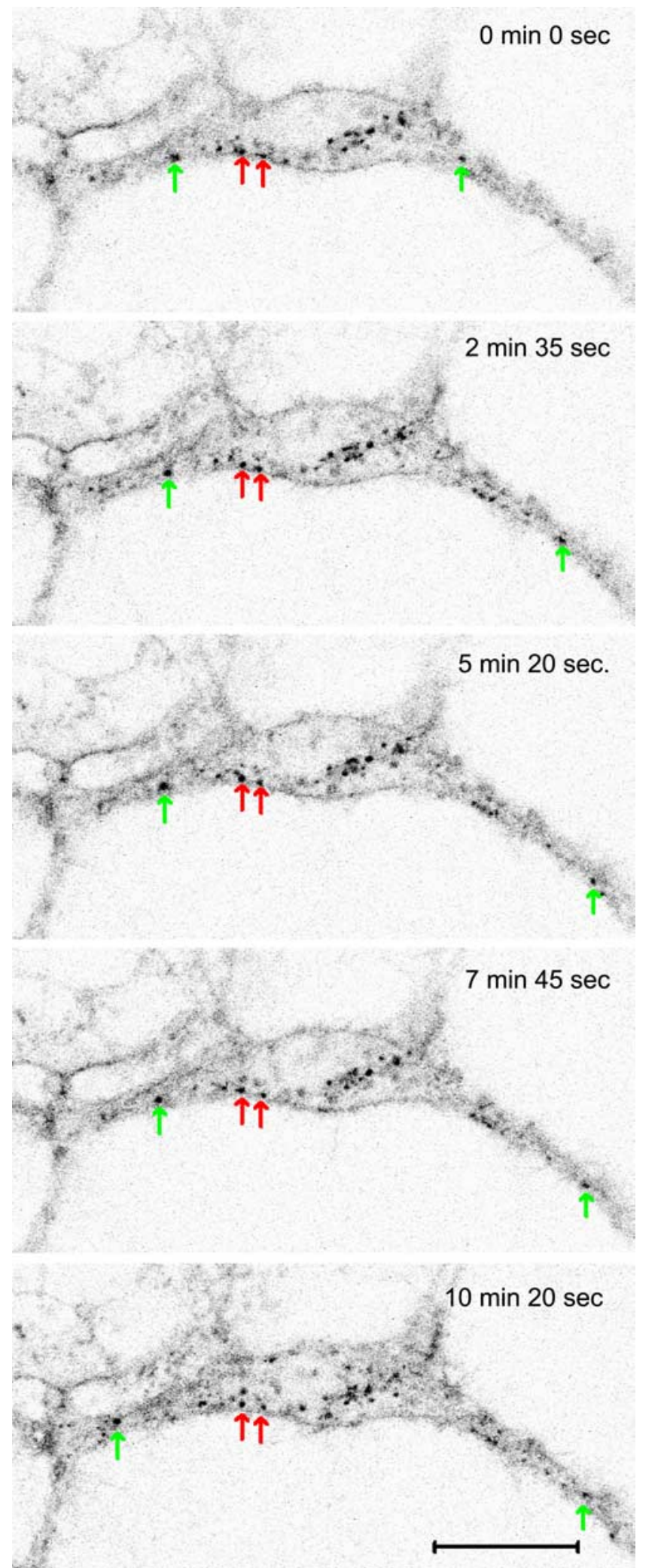

Figure 11. Tracking of internalized JHC 1-64/DAT-positive vesicles in cultured midbrain dopaminergic neurons. The neurons (6 DIV) were labeled with $5 \mathrm{~nm} \mathrm{JHC} 1-64$ at $37^{\circ} \mathrm{C}$ for $1 \mathrm{~h}$ to allow labeling and internalization of the DAT/JHC 1-64 complex. Subsequently, time laps were performed with 300 pictures in 20 min using a heated stage $\left(37^{\circ} \mathrm{C}\right)$ on the LSM510 confocal microscope. JHC 1-64 was visualized by using a $543 \mathrm{~nm}$ HeNe laser for excitation and a $>585 \mathrm{~nm}$ long-pass filter for recording of fluorescence. The images show the fluorescence on a gray scale with darkest pixels representing the largest fluorescence. A representative example of a movie resulting from this protocol is provided in the supplemental material (supplemental Movie 2, available at www.jneurosci.org). Se- dissociation-rate permitting tracking of DAT molecules in live cells over even an extended period of time.

It is a potential concern that by using the fluorescently tagged cocaine analogs we study an inhibitor-occupied transporter. Previously, it has been suggested that cocaine causes acute upregulation of DAT surface expression in transfected HEK293 cells (Daws et al., 2002). Thus, inhibitor binding might affect DAT trafficking; however, although the effect of cocaine on DAT trafficking was significant, the magnitude of the response was relatively modest (Daws et al., 2002). In addition, cocaine was found not to affect PMA-induced DAT internalization in GFPexpressing MDCK cells (Daniels and Amara, 1999). We were also unable to see any effect of JHC 1-64 on surface expression and constitutive trafficking of HA-tagged DAT in HEK293 cells; hence the effect of JHC 1-64 on endogenous DAT trafficking is likely to be absent or very minor.

Labeling of midbrain dopaminergic neurons with either JHC 1-64 or MFZ 9-18 revealed a uniform distribution of the DAT with labeling of somas, extensions, and varicosities. $Z$-stacking analysis allowed us to correlate staining with neuronal morphology and validate the widespread labeling of DAT in the individual neurons (Fig. 6). As expected, neurons that were stained with JHC 1-64 also displayed staining for VMAT2; however, whereas the VMAT2 staining localizes solely to varicosities along the extensions, JHC 1-64 staining, and thus DAT, was present not only in the varicosities but also along the extensions as well as in the plasma membrane of the soma. Of interest, the network of neuronal extensions in the DAT-positive neurons is likely to be mostly axonal as supported by costainings of our culture for DAT and for the dendritic marker MAP2 (supplemental Fig. S7, available at www.jneurosci.org as supplemental material).

Although the expression pattern in cultured neurons might not be identical to that found in situ, it is interesting to consider our observations in context of earlier EM studies in rat brain (Nirenberg et al., 1996, 1997; Hersch et al., 1997). These studies also provided evidence for widespread expression of DAT in axons as well as in dendrites. Moreover, they suggested perisynaptic/extrasynaptic localization of DAT challenging the classical paradigm of preferential presynaptic localization of DAT (Nirenberg et al., 1996, 1997; Hersch et al., 1997). Altogether, the present data add further support to the notion that DAT is not fulfilling its indispensable role in maintaining low extracellular levels of dopamine by being discretely expressed close to the dopamine release sites but rather by being present throughout the plasma membrane in the dopaminergic neurons.

This view is further supported by our FRAP measurements providing evidence that the JHC 1-64-labeled DAT in cultured dopaminergic neurons is highly mobile with mobile fractions constituting $>70 \%$ of the JHC 1-64-labeled transporter molecules both in varicosities and in the neuronal extensions. The calculated diffusion coefficients $\left(0.5-1.1 \times 10^{-9} \mathrm{~cm}^{2} / \mathrm{s}\right)$ were consistent with a relatively freely diffusing protein in the membrane (Lippincott-Schwartz et al., 2001). Of note, these values resembled more the values that we obtained previously for EGFPtagged DAT in HEK293 cells $\left(\sim 0.4 \times 10^{-9} \mathrm{~cm}^{2} / \mathrm{s}\right)$ than for EGFP-tagged DAT expressed in neuronally derived N2a cells

$\leftarrow$

lected images from this movie at indicated time points are shown. The larger fraction of the vesicles seemed to be stationary (exemplified by the 2 vesicles indicated by the red arrows), whereas a smaller fraction underwent often rapid movements over rather long distances during the observation period (vesicles indicated with green arrows). Scale bar, $20 \mu \mathrm{m}$. 
$\left(\sim 0.1 \times 10^{-9} \mathrm{~cm}^{2} / \mathrm{s}\right)$ (Adkins et al., 2007). Thus, DAT apparently displays less restricted diffusion in dopaminergic neurons and thereby in a native environment compared with a transfected neuronal cell line.

In heterologous cell lines, it is well established that activation of PKC by PMA leads to DAT internalization. The effect is not caused by direct phosphorylation of DAT (Granas et al., 2003) but more likely the result of ubiquitination of a cluster of lysines in the $\mathrm{N}$ terminus (Miranda et al., 2007). Although well established in heterologous cells, the effect on internalization has not yet been assessed for endogenously expressed DAT in cultured neurons. Interestingly, the current data strongly support that DAT is not subject to regulation by PKC in neurons as we were unable to see any difference compared with control after PMA stimulation or inhibition of PKC with staurosporine. Moreover, the lack of an effect in response to modulation of PKC activity was supported by dopamine uptake experiments showing no change in response to PMA and two different PKC inhibitors. The lack of an effect was also unlikely caused by enhanced tyrosine kinase activity, which was suggested to inhibit PMA-mediated redistribution of the GABA transporter-1 (Quick et al., 2004); hence, pretreatment with the tyrosine kinase inhibitor genistein did not uncover an effect of PMA on DAT in the neurons (data not shown). Of note, our findings agree with recent observations in cultured prenatal midbrain neurons that were transfected with epitope-tagged DAT and in which no visible effect of PMA was seen (Sorkina et al., 2006). However, PMA treatment of cocultures of midbrain and striatal neurons, as well as PMA treatment of striatal, synaptosomal preparations, was previously found to reduce DAT uptake activity (Vaughan et al., 1997; Chi and Reith, 2003; Hoover et al., 2007). Thus, although we were unable to see PKC-mediated regulation in cultured midbrain neurons we cannot exclude that under certain conditions endogenous DAT might be subject to regulation by this kinase.

While unable to observe an effect of PKC modulation, we observed constitutive, temperature-dependent intracellular accumulation of JHC 1-64-labeled transporter over time. We were only able to visualize the constitutive internalization in the soma and proximal neuronal extensions. This might suggest that the internalization only occurs here; however, we cannot exclude that we do not have sufficient resolution to see endocytosis in the thin neurites. Constitutive DAT internalization has been shown before in transfected heterologous cells (Holton et al., 2005; Sorkina et al., 2005) and a C-terminal motif has been suggested to mediate this constitutive internalization (Holton et al., 2005). In this study, we demonstrate that constitutive trafficking is indeed not restricted to heterologously expressed transporter but also is seen for DAT expressed in its native environment and that this internalization likely is mediated via a dynamin-dependent pathway. Dynamins have been identified as a key component and marker of clathrin-mediated endocytosis (van der Bliek et al., 1993; Robinson, 1994); hence, it is likely that constitutive endocytosis of endogenous DAT follows the same pathway as that suggested previously for heterologously expressed DAT (Sorkina et al., 2005; Rappoport, 2008). However, it is important to note that nonclathrin but dynamin-dependent pathways such as raftmediated endocytosis also have been identified and may be responsible for or contribute to constitutive DAT endocytosis (Lajoie and Nabi, 2007). Of further interest, we obtained data suggesting that internalized JHC 1-64-labeled DAT colocalized in part with EGFP-Rab5A, a small GTPase localized to the early endocytic pathway (Zerial and McBride, 2001; Deneka et al., 2003; Lavezzari et al., 2004) and with the transferrin receptor, another marker of the early endocytic pathway (Blanpied et al., 2002). The colocalization was only partial, which is not surprising given that constitutive endocytosis is not a synchronized event elicited by a specific stimuli; hence, it would be expected that we after the incubation period also will see JHC 1-64-labeled DAT in other endosomal compartments along the endocytic pathway. For transferrin, the colocalization seemed to diminish over time possibly reflecting differential postendocytic sorting of DAT and the transferrin receptor.

The visualization of endocytosed JHC 1-64-labeled transporter suggests furthermore that cultured dopaminergic neurons contain a pool of intracellular transporter. Live imaging of the internalized transporter allowed us to follow movements of the intracellular vesicles. In this way, we identified JHC 1-64positive vesicles that either were essentially immobilized or undergoing rapid movements during the observation period. Future studies are required to characterize the functional implications of these observations; however, it is tempting to speculate that the endocytosed JHC 1-64-labeled DAT unravel a recruitable pool of transporters that might permit rapid adaptation of the neuron to immediate changes in the need for neurotransmitter reuptake. Interestingly, a pool of intracellular transporters has before been suggested to exist for DAT (Buckley et al., 2000; Johnson et al., 2005) as well as for the homologous GABA transporter-1 (Wang and Quick, 2005).

\section{References}

Adkins EM, Samuvel DJ, Fog JU, Eriksen J, Jayanthi LD, Vaegter CB, Ramamoorthy S, Gether U (2007) Membrane mobility and microdomain association of the dopamine transporter studied with fluorescence correlation spectroscopy and fluorescence recovery after photobleaching. Biochemistry 46:10484-10497.

Blakely RD, Bauman AL (2000) Biogenic amine transporters: regulation in flux. Curr Opin Neurobiol 10:328-336.

Blanpied TA, Scott DB, Ehlers MD (2002) Dynamics and regulation of clathrin coats at specialized endocytic zones of dendrites and spines. Neuron 36:435-449.

Buckley KM, Melikian HE, Provoda CJ, Waring MT (2000) Regulation of neuronal function by protein trafficking: a role for the endosomal pathway. J Physiol 525:11-19.

Cha JH, Zou MF, Adkins EM, Rasmussen SG, Loland CJ, Schoenenberger B, Gether U, Newman AH (2005) Rhodamine-labeled 2beta-carbomethoxy3beta-(3,4-dichlorophenyl)tropane analogues as high-affinity fluorescent probes for the dopamine transporter. J Med Chem 48:7513-7516.

Chen NH, Reith ME, Quick MW (2004) Synaptic uptake and beyond: the sodium- and chloride-dependent neurotransmitter transporter family SLC6. Pflugers Arch 447:519-531.

Chi L, Reith ME (2003) Substrate-induced trafficking of the dopamine transporter in heterologously expressing cells and in rat striatal synaptosomal preparations. J Pharmacol Exp Ther 307:729-736.

Daniels GM, Amara SG (1999) Regulated trafficking of the human dopamine transporter. Clathrin-mediated internalization and lysosomal degradation in response to phorbol esters. J Biol Chem 274:35794-35801.

Daws LC, Callaghan PD, Morón JA, Kahlig KM, Shippenberg TS, Javitch JA, Galli A (2002) Cocaine increases dopamine uptake and cell surface expression of dopamine transporters. Biochem Biophys Res Commun 290:1545-1550.

Deneka M, Neeft M, van der Sluijs P (2003) Regulation of membrane transport by rab GTPases. Crit Rev Biochem Mol Biol 38:121-142.

di Porzio U, Daguet MC, Glowinski J, Prochiantz A (1980) Effect of striatal cells on in vitro maturation of mesencephalic dopaminergic neurones grown in serum-free conditions. Nature 288:370-373.

di Porzio U, Rougon G, Novotny EA, Barker JL (1987) Dopaminergic neurons from embryonic mouse mesencephalon are enriched in culture through immunoreaction with monoclonal antibody to neural specific protein 4 and flow cytometry. Proc Natl Acad Sci U S A 84:7334-7338.

Dittgen T, Nimmerjahn A, Komai S, Licznerski P, Waters J, Margrie TW, Helmchen F, Denk W, Brecht M, Osten P (2004) Lentivirus-based ge- 
netic manipulations of cortical neurons and their optical and electrophysiological monitoring in vivo. Proc Natl Acad Sci U S A 101:18206-18211.

Gainetdinov RR, Caron MG (2003) Monoamine transporters: from genes to behavior. Annu Rev Pharmacol Toxicol 43:261-284.

Gallegos LL, Kunkel MT, Newton AC (2006) Targeting protein kinase C activity reporter to discrete intracellular regions reveals spatiotemporal differences in agonist-dependent signaling. J Biol Chem 281:30947-30956.

Garcia BG, Wei Y, Moron JA, Lin RZ, Javitch JA, Galli A (2005) Akt is essential for insulin modulation of amphetamine-induced human dopamine transporter cell-surface redistribution. Mol Pharmacol 68:102-109.

Gether U, Andersen PH, Larsson OM, Schousboe A (2006) Neurotransmitter transporters: molecular function of important drug targets. Trends Pharmacol Sci 27:375-383.

Granas C, Ferrer J, Loland CJ, Javitch JA, Gether U (2003) N-terminal truncation of the dopamine transporter abolishes phorbol ester- and substance P receptor-stimulated phosphorylation without impairing transporter internalization. J Biol Chem 278:4990-5000.

Hansen SH, Sandvig K, van Deurs B (1993) Clathrin and HA2 adaptors: effects of potassium depletion, hypertonic medium, and cytosol acidification. J Cell Biol 121:61-72.

Hersch SM, Yi H, Heilman CJ, Edwards RH, Levey AI (1997) Subcellular localization and molecular topology of the dopamine transporter in the striatum and substantia nigra. J Comp Neurol 388:211-227.

Heuser JE, Anderson RG (1989) Hypertonic media inhibit receptormediated endocytosis by blocking clathrin-coated pit formation. J Cell Biol 108:389-400.

Holton KL, Loder MK, Melikian HE (2005) Nonclassical, distinct endocytic signals dictate constitutive and PKC-regulated neurotransmitter transporter internalization. Nat Neurosci 8:881-888.

Hoover BR, Everett CV, Sorkin A, Zahniser NR (2007) Rapid regulation of dopamine transporters by tyrosine kinases in rat neuronal preparations. J Neurochem 101:1258-1271.

Ingram SL, Prasad BM, Amara SG (2002) Dopamine transporter-mediated conductances increase excitability of midbrain dopamine neurons. Nat Neurosci 5:971-978.

Johnson LA, Furman CA, Zhang M, Guptaroy B, Gnegy ME (2005) Rapid delivery of the dopamine transporter to the plasmalemmal membrane upon amphetamine stimulation. Neuropharmacology 49:750-758.

Lajoie P, Nabi IR (2007) Regulation of raft-dependent endocytosis. J Cell Mol Med 11:644-653.

Lavezzari G, McCallum J, Dewey CM, Roche KW (2004) Subunit-specific regulation of NMDA receptor endocytosis. J Neurosci 24:6383-6391.

Leander Johansen J, Dagø L, Tornøe J, Rosenblad C, Kusk P (2005) A new versatile and compact lentiviral vector. Mol Biotechnol 29:47-56.

Lippincott-Schwartz J, Snapp E, Kenworthy A (2001) Studying protein dynamics in living cells. Nat Rev Mol Cell Biol 2:444-456.

Melikian HE, Buckley KM (1999) Membrane trafficking regulates the activity of the human dopamine transporter. J Neurosci 19:7699-7710.

Miranda M, Dionne KR, Sorkina T, Sorkin A (2007) Three ubiquitin conjugation sites in the amino terminus of the dopamine transporter mediate protein kinase $\mathrm{C}$-dependent endocytosis of the transporter. Mol Biol Cell 18:313-323.

Morón JA, Zakharova I, Ferrer JV, Merrill GA, Hope B, Lafer EM, Lin ZC, Wang JB, Javitch JA, Galli A, Shippenberg TS (2003) Mitogen-activated protein kinase regulates dopamine transporter surface expression and dopamine transport capacity. J Neurosci 23:8480-8488.

Naldini L, Blömer U, Gage FH, Trono D, Verma IM (1996a) Efficient transfer, integration, and sustained long-term expression of the transgene in adult rat brains injected with a lentiviral vector. Proc Natl Acad Sci U S A 93:11382-11388.

Naldini L, Blömer U, Gallay P, Ory D, Mulligan R, Gage FH, Verma IM, Trono D (1996b) In vivo gene delivery and stable transduction of nondividing cells by a lentiviral vector. Science 272:263-267.

Nirenberg MJ, Vaughan RA, Uhl GR, Kuhar MJ, Pickel VM (1996) The dopamine transporter is localized to dendritic and axonal plasma membranes of nigrostriatal dopaminergic neurons. J Neurosci 16:436-447.

Nirenberg MJ, Chan J, Vaughan RA, Uhl GR, Kuhar MJ, Pickel VM (1997) Immunogold localization of the dopamine transporter: an ultrastructural study of the rat ventral tegmental area. J Neurosci 17:5255-5262.

Quick MW, Hu J, Wang D, Zhang HY (2004) Regulation of a gammaaminobutyric acid transporter by reciprocal tyrosine and serine phosphorylation. J Biol Chem 279:15961-15967.

Rappoport JZ (2008) Focusing on clathrin-mediated endocytosis. Biochem J 412:415-423.

Rayport S, Sulzer D, Shi WX, Sawasdikosol S, Monaco J, Batson D, Rajendran G (1992) Identified postnatal mesolimbic dopamine neurons in culture: morphology and electrophysiology. J Neurosci 12:4264-4280.

Rees S, Coote J, Stables J, Goodson S, Harris S, Lee MG (1996) Bicistronic vector for the creation of stable mammalian cell lines that predisposes all antibiotic-resistant cells to express recombinant protein. Biotechniques 20:102-104, 106, 108-110.

Robinson MS (1994) The role of clathrin, adaptors and dynamin in endocytosis. Curr Opin Cell Biol 6:538-544.

Saunders C, Ferrer JV, Shi L, Chen J, Merrill G, Lamb ME, Leeb-Lundberg LM, Carvelli L, Javitch JA, Galli A (2000) Amphetamine-induced loss of human dopamine transporter activity: an internalization-dependent and cocaine-sensitive mechanism. Proc Natl Acad Sci U S A 97:6850-6855.

Silva NL, Mariani AP, Harrison NL, Barker JL (1988) 5,7Dihydroxytryptamine identifies living dopaminergic neurons in mesencephalic cultures. Proc Natl Acad Sci U S A 85:7346-7350.

Sorkina T, Hoover BR, Zahniser NR, Sorkin A (2005) Constitutive and protein kinase $\mathrm{C}$-induced internalization of the dopamine transporter is mediated by a clathrin-dependent mechanism. Traffic 6:157-170.

Sorkina T, Miranda M, Dionne KR, Hoover BR, Zahniser NR, Sorkin A (2006) RNA interference screen reveals an essential role of Nedd4-2 in dopamine transporter ubiquitination and endocytosis. J Neurosci 26:8195-8205.

Torres GE, Amara SG (2007) Glutamate and monoamine transporters: new visions of form and function. Curr Opin Neurobiol 17:304-312.

Torres GE, Gainetdinov RR, Caron MG (2003) Plasma membrane monoamine transporters: structure, regulation and function. Nat Rev Neurosci 4:13-25.

van der Bliek AM, Redelmeier TE, Damke H, Tisdale EJ, Meyerowitz EM, Schmid SL (1993) Mutations in human dynamin block an intermediate stage in coated vesicle formation. J Cell Biol 122:553-563.

Vaughan RA, Huff RA, Uhl GR, Kuhar MJ (1997) Protein kinase C-mediated phosphorylation and functional regulation of dopamine transporters in striatal synaptosomes. J Biol Chem 272:15541-15546.

Violin JD, Zhang J, Tsien RY, Newton AC (2003) A genetically encoded fluorescent reporter reveals oscillatory phosphorylation by protein kinase C. J Cell Biol 161:899-909.

Wang D, Quick MW (2005) Trafficking of the plasma membrane gammaaminobutyric acid transporter GAT1. Size and rates of an acutely recycling pool. J Biol Chem 280:18703-18709.

Yguerabide J, Schmidt JA, Yguerabide EE (1982) Lateral mobility in membranes as detected by fluorescence recovery after photobleaching. Biophys J 40:69-75.

Zerial M, McBride H (2001) Rab proteins as membrane organizers. Nat Rev Mol Cell Biol 2:107-117.

Zhou P, Porcionatto M, Pilapil M, Chen Y, Choi Y, Tolias KF, Bikoff JB, Hong EJ, Greenberg ME, Segal RA (2007) Polarized signaling endosomes coordinate BDNF-induced chemotaxis of cerebellar precursors. Neuron 55:53-68.

Zomot E, Bendahan A, Quick M, Zhao Y, Javitch JA, Kanner BI (2007) Mechanism of chloride interaction with neurotransmitter:sodium symporters. Nature 449:726-730.

Zufferey R, Nagy D, Mandel RJ, Naldini L, Trono D (1997) Multiply attenuated lentiviral vector achieves efficient gene delivery in vivo. Nat Biotechnol 15:871-875. 